\title{
The cohesin regulator Stag1 promotes cell plasticity through heterochromatin regulation.
}

Dubravka Pezic ${ }^{1}$, Sam Weeks ${ }^{1}$, Wazeer Varsally ${ }^{1}$, Pooran S. Dewari ${ }^{2}$, Steven Pollard ${ }^{2}$, Miguel R. Branco ${ }^{3}$, Suzana Hadjur ${ }^{1 *}$

1 Research Department of Cancer Biology, Cancer Institute, University College London, 72 Huntley Street, London, United Kingdom

2 MRC Centre for Regenerative Medicine, University of Edinburgh, Edinburgh, United Kingdom

3 Blizard Institute, Barts and The London School of Medicine and Dentistry, QMUL, London, United Kingdom

*Correspondence: s.hadjur@ucl.ac.uk 


\section{SUMMARY}

2 Fundamental biological processes such as embryo development and stem cell control

3 rely on cellular plasticity. We present a role for the cohesin regulator, Stag1 in cellular

4 plasticity control via heterochromatin regulation. Stag1 localises to heterochromatin

5 domains and repetitive sequences in embryonic stem (ES) cells and contains intrinsically

6 disordered regions in its divergent terminal ends which promote heterochromatin

7 compaction. ES cells express Stag1 protein isoforms lacking the disordered ends and

8 fluctuations in isoform abundance skews the cell state continuum towards increased

9 differentiation or reprogramming. The role for Stag1 in heterochromatin condensates and

10 nucleolar function is dependent on its unique N-terminus. Stag1 ${ }^{\mathrm{N} \Delta}$ ESCs

11 have decompacted chromatin and reprogram towards totipotency, exhibiting MERVL de-

12 repression, reduced nucleolar transcription and decreased translation. Our results move

13 beyond protein-coding gene regulation via chromatin loops into a new role for Stag1 in

14 heterochromatin and nucleolar function and offer fresh perspectives on its contribution

15 to cell identity and disease.

\section{KEY WORDS}

19 Cellular plasticity, heterochromatin, repetitive elements, nucleolus, Stag1, translation 


\section{INTRODUCTION}

21 Cellular populations consist of mixtures of cells across a continuum of states and such

22 heterogeneity underlies responsiveness to changing conditions. Fundamental biological

23 processes including embryo development, stem cell control and cancer rely on

24 conversion between states. While transcriptional states are ever-increasingly well

25 described (Wagner et al., 2016), the mechanisms that control the stability of a given state

26 are less well understood. The chromatin landscape with its inherent dynamics (Cho et al.,

27 2018; Finn et al., 2019; Nozaki et al., 2017; Ricci et al., 2015) and complex 3-dimensional

28 (3D) organization (Bonev et al., 2017; Cardozo Gizzi et al., 2019; Dekker and Mirny, 2016;

29 Nagano et al., 2017; Schlesinger and Meshorer, 2019) can act as a mechanism to support

30 transcriptional heterogeneity (Mateo et al., 2019; Rodriguez et al., 2019) and the

31 chromatin proteins that regulate this landscape may play key roles in cell plasticity

32 (Meshorer et al., 2006).

33 Genomes are partitioned into distinct functional domains within the nucleus

34 (Bickmore and van Steensel, 2013; Bonev and Cavalli, 2016). A prominent feature of

35 nuclear organization is the compact heterochromatin that accumulates at the periphery

36 of the nucleus, around the nucleolus and at distinct foci within the nucleoplasm (Guelen

37 et al., 2008; Németh et al., 2010; Padeken and Heun, 2014; Quinodoz et al., 2018).

38 Heterochromatin is formed at repetitive sequences, is tightly associated with repressive

39 histone modifications like methylation of histone $\mathrm{H} 3$ at lysine 9 (H3K9me2,3), and a

40 specific set of proteins, including Heterochromatin Protein 1 (HP1) that together condense

41 chromatin to maintain repression (Allshire and Madhani, 2018). Further, sequestration of

42 condensed chromatin into dynamic phase-separated condensates (Larson et al., 2017;

43 Strom et al., 2017) contributes to heterochromatin-mediated silencing. Heterochromatin

44 organization plays a key role in cell identity and is rapidly remodelled during ES cell

45 differentiation and embryo development. Decompaction of heterochromatin and

46 subsequent de-repression of repetitive elements drives reprogramming towards totipotent

47 embryos, while progressive compaction is associated with terminal differentiation (Ahmed

48 et al., 2010; Borsos and Torres-Padilla, 2016; Martin et al., 2006; Meshorer et al., 2006;

49 Novo et al., 2016). 
Cohesin is a ubiquitously expressed, multi-subunit protein complex that has fundamental roles in cell biology including sister chromosome cohesion, 3D chromatin topology and regulation of cell identity (Cuartero et al., 2018; Horsfield et al., 2007; Kline et al., 2018; Leiserson et al., 2015; Romero-Pérez et al., 2019; Viny et al., 2019). Much of our understanding of how cohesin contributes to cell identity has been studied in the context of its roles in protein-coding gene expression and 3D organization of interphase chromatin structure (Hadjur et al., 2009; Kagey et al., 2010; Mishiro and Tsutsumi, 2009; Misulovin et al., 2007; Parelho et al., 2008; Phillips-Cremins et al., 2013; Rao et al., 2014; Vietri Rudan et al., 2015; Wendt et al., 2008). Indeed, loss of cohesin and its regulators results in a dramatic loss of chromatin topology at the level of Topologically Associated Domains (TAD) and chromatin loops, with only modest changes to gene expression (Haarhuis et al., 2017; Rao et al., 2017; Schwarzer et al., 2017; Seitan et al., 2013; Sofueva et al., 2013; Wutz et al., 2017; Zuin et al., 2014). This suggests that cohesin's roles in development and disease extend beyond gene expression regulation and highlight the need to re-evaluate how cohesin regulators shape the structure and function of the genome.

The association of cohesin with chromosomes is tightly controlled by several regulators, including the Stromalin Antigen protein (known as Stag or SA), which has been widely implicated in cell identity regulation and disease development (Cuadrado et al., 2019; Lehalle et al., 2017; Leiserson et al., 2015; Soardi et al., 2017; Viny et al., 2019; Yuan et al., 2019). Stag proteins interact with the Rad21 subunit of cohesin and mediate its association with DNA and CTCF (Hara et al., 2014; Li et al., 2020; Orgil et al., 2015;

72 Xiao et al., 2011). Mammalian cells have three Stag paralogs, Stag1, 2 and 3. These

73 show $>90 \%$ conservation of sequence in their central domain yet perform distinct 74 functions (Canudas and Smith, 2009; Kojic et al., 2018; Remeseiro et al., 2012a; Winters 75 et al., 2014). It is likely that the divergent $\mathrm{N}$ - and C-terminal regions provide functional 76 specificity. For example, the N-terminus of Stag1 contains a unique AT-hook (Bisht et al., 77 2013) which is required for its preferential participation in telomere cohesion (Canudas 78 and Smith, 2009). The underlying mechanisms by which Stag proteins and their divergent ends influence cell identity are still largely unknown. 
Here we report that Stag1 is the dominant paralogue in ES cells and supports

81 pluripotency by regulating heterochromatin organization. We discover that ES cells

82 regulate the level of Stag1 protein and the proportion of its divergent $\mathrm{N}$ and $\mathrm{C}$-terminal

83 ends, which contain disordered regions. This naturally occurring Stag1 protein

84 heterogeneity supports a continuum of functionally distinct cellular states within the

85 population. Changing the balance in the levels of Stag1 isoforms leads to conversion

86 between cell states, with the loss of the $\mathrm{N}$-terminus favoring a reprogrammed, totipotent

87 state and decompaction of heterochromatin condensates and the loss of the C-terminus

88 priming cells towards exit from pluripotency through gene expression deregulation. These

89 results define specialised, non-redundant roles for the divergent ends. Mechanistically,

90 the N-terminus of Stag1 represses reprogramming to totipotent 2-cell-like (2C-L) cells by

91 maintaining nucleolar structure and function. We uncover Nucleolin and Trim28 as direct

92 interactors of Stag1 and show that cells selectively expressing Stag1 isoforms lacking the

93 N-terminal AT-hook domain exhibit reduced nascent nucleolar transcription and a

94 decrease in global translation. Our results take us beyond protein coding gene regulation

95 via chromatin loops into a new role for Stag1 in the regulation of heterochromatin and

96 nucleolar structure and function. Importantly, by identifying changes to translation control

97 upon Stag1 loss in stem cells, we open a new perspective by which Stag proteins and

98 cohesin regulation can impact cell identity and disease. 


\section{RESULTS}

100 A functional change in cohesin regulation in cells of different potential.

101 We analyzed the expression levels of cohesin regulators in embryonic stem cells (ES) at 102 different stages of pluripotency. During the transition between naïve (2i) and primed 103 (EpiLC) pluripotency in vitro, levels of the core cohesin subunits Smc1 and Smc3 do not 104 change, while Stag1 becomes downregulated and Stag2 becomes upregulated (Figures 105 1A, S1A, B). This was confirmed at the protein level, where we observe a 2-3-fold higher 106 level of chromatin-associated Stag1 compared to Stag2 in naïve ES cells, while Stag2 107 levels are 5-10-fold higher in EpiLCs (Figures 1B, S1C). These results, together with 108 similar observations (Cuadrado et al., 2019), identify Stag1 as the dominant paralog in 109 naïve ES cells and suggest that a switch between Stag1 and Stag2 may represent a 110 functionally relevant change in cohesin regulation at different stages of pluripotency.

\section{Stag1 supports the naïve pluripotent state.}

113 To investigate the functional importance of Stag1 in the regulation of pluripotency, we 114 established a Stag1 RNA knockdown (KD, 'siSA1-SP', Methods) strategy using siRNAs.

115 This resulted in a significant reduction of Stag1 at the mRNA and protein levels (4-5-fold, 116 8-10-fold, respectively), in both serum-grown (FCS) and naïve (2i) ES cells without 117 affecting the cell cycle (Figures 1C, S1D, E). Using Nanog as a marker of naïve 118 pluripotency, we observed a significant downregulation of Nanog mRNA and protein 119 levels within 24hrs of Stag1 KD in all ES populations (Figures 1D, E, S1F), suggesting 120 that Stag1 may be functionally required for pluripotency. Indeed, a global analysis of the 121 ES transcriptome upon siRNA-mediated Stag1 KD revealed that 375 genes were up- and 122205 genes were down-regulated by at least 2-fold (Figure 1F). Among the downregulated 123 group were several genes known to have key roles in the maintenance of pluripotency, 124 including Nanog, Tbx3, Esrrb, Klf2, KIf4, Prdm14, Tfcp2I1, Lefty2. Notably, we did not 125 detect a change in expression of Oct4 or Sox2, and Zfp42 was minimally affected. 126 Moreover, we also observed both an upregulation of genes associated with exit from the 127 pluripotent state (Dppa3, Fgf5) as well as differentiation-specific genes such as Pou3f1 
128 (Oct6) and Sox11 (Figure 1F). Single-gene analysis revealed consistent, albeit low fold-

129 change trends across our biological replicates, thus we used Gene Set Enrichment

130 Analysis (GSEA) (Mootha et al., 2003; Subramanian et al., 2005) to detect modest but

131 coordinate changes in the expression of groups of functionally related genes. This

132 revealed a robust gene signature of exit from pluripotency and enrichment for genes

133 associated with primed pluripotency upon Stag1 KD across all biological replicates

134 (Figures 1G, S1G).

135 The loss of the naïve transcriptional programme upon Stag1 KD suggests that ES 136 cells may require Stag1 for the maintenance of self-renewal. To test this, we plated cells

137 in self-renewal conditions at clonal density and determined the proportion of 138 undifferentiated cells upon Stag1 KD by measuring the area occupied by the colonies 139 with high alkaline phosphatase activity (AP+). In scrambled siRNA-treated controls, 52\% 140 of plated cells retain their naïve state, identified by $\mathrm{AP}+$ colonies (Figure $\mathrm{S} 1 \mathrm{H}$ ). However, 141 upon Stag1 KD, both the proportion of AP+ colonies and the area they occupy decreased 142 by $20 \%$, indicating that ES cells have a reduced self-renewal ability in the absence of 143 Stag1 (Figures 1H, S1H). As independent validation of these results, we used 144 CRISPR/Cas9 to knock-in an mNeonGreen-FKBP12 ${ }^{\mathrm{F} 36 \mathrm{~V}}$ tag (Nabet et al., 2018) at the C145 terminus of both alleles of the endogenous Stag1 locus (SA1 ${ }^{\text {NG_FKBP }}$ ) in ES cells (Figures 146 1I, S1I-K). Upon dTAG addition, Stag1 protein is robustly degraded in SA1 ${ }^{\text {NG_FKBP }}$ ES 147 clones (Figure 1I, S1K). As was observed with siRNA treatment, dTAG-mediated 148 degradation of Stag1 led to a $50 \%$ reduction of self-renewal potential (Figure 1J). 149 Together, our results are consistent with a requirement for Stag1 in the control of naïve 150 pluripotency and provide an opportunity to discover the mechanisms of Stag1 actions.

\section{STAG1 localizes to AT-rich heterochromatin.}

153 To begin to understand how STAG1 contributes to pluripotency, we investigated the 154 subcellular localization of endogenous STAG1. Live cell imaging of Hoechst-labelled 155 Stag1 ${ }^{\text {NG_FKBP }}$ ES cells revealed the expected and predominant localisation of STAG1 in 
156 the nucleus (Figures 2A, B). Interestingly, STAG1 was not uniformly distributed within the

157 nucleoplasm. In addition to a dispersed nucleoplasmic localisation pattern, we observed

158 STAG1 colocalization with Hoechst-dense regions. These included colocalization at large

159 Hoechst-dense foci (Figure 2A, top cell), within the interior of the nucleolus (Figure 2A,

160 top cell) and at the periphery of the nucleolus (Figure 2A, all cells). The mean intensity of

161 STAG1 (as measured by mNeonGreen signal) was significantly enriched within Hoechst-

162 dense foci compared to the whole nucleus, and the signal was sensitive to treatment with

163 dTAG (Figure 2B). We made similar observations of STAG1 localization at DAPI-dense

164 foci in cells expressing Dox-inducible GFP-tagged full-length Stag1 (SA1 ${ }^{\mathrm{FL}}$-GFP) (Figure

165 S2A, B). We note that repressive heterochromatin domains are readily observed by

166 staining with AT-rich DNA dyes (ie. DAPI and Hoechst) and are organized around the

167 nucleolus, in discreet foci within the nucleoplasm, or tethered to the nuclear periphery

168 (Padeken and Heun, 2014; Quinodoz et al., 2018). Thus, the profile of STAG1 within ES

169 cells is consistent with its localization to AT-rich heterochromatin. Given the presence of

170 an AT-hook within STAG1 and the importance of heterochromatin regulation in

171 development, we investigated whether STAG1 may have a role in heterochromatin

172 structure.

\section{STAG1 interacts with heterochromatin proteins and repetitive DNA.}

175 Since STAG1 was localised to nuclear heterochromatin domains, we investigated

176 whether it was also interacting with heterochromatin proteins and bound to genomic

177 sequences known to form heterochromatin, such as repeats. Constitutive

178 heterochromatin is characterized by the binding of HP1a to H3K9me2/) and plays a

179 critical role in silencing of repetitive DNA elements (Allshire and Madhani, 2018) and

180 nuclear organization (Larson et al., 2017). The periphery of the nucleolus accumulates

181 marks of constitutive heterochromatin coincident with transcriptionally inactive rDNA

182 repeats. Nucleolin is a major nucleolar protein which controls the organization of

183 nucleolar chromatin, rDNA transcription and ribosome assembly and plays important

184 roles during development and in ES cells (Kresoja-Rakic and Santoro, 2019; Percharde

185 et al., 2018). We observed nuclear colocalization between STAG1 and HP1a in dox- 
186 induced $\mathrm{SA} 1^{\mathrm{FL}}$-GFP cells around DAPI-dense foci (Figures S2A, B). Further, using 187 chromatin colmmunoprecipitation (colP), we show that STAG1 interacts with both HP1a 188 and Nucleolin in ES cells (Figure 2C, S2C).

189 Previous studies have analysed STAG1 binding profiles in mouse ES cells and 190 have primarily focused on its association with protein-coding genes (Cuadrado et al., 191 2019). A thorough investigation of STAG1 binding to repetitive sequences has not been 192 conducted. Thus, we re-analysed STAG1 chromatin immunoprecipitation followed by 193 sequencing (ChIP-seq) experiments to calculate the proportion of STAG1 peaks that 194 overlapped genes (based on promoter and exon features), repeats (within the Repeat 195 Masker annotation) introns and intergenic regions not already represented by repeats or 196 genes. Of the 18,600 STAG1 peaks identified, the majority (76\%) are bound to genomic 197 elements that are distinct from protein-coding genes with a significant proportion of 198 binding sites at repetitive elements and intergenic regions (Figure 2D). Together with the 199 localizations observed by microscopy, this suggests that the role of STAG1 in ES cells 200 may extend beyond protein-coding gene regulation. While STAG1 binding is not enriched 201 compared to all genomic repeats, we asked whether specific repeat families might be 202 enriched for STAG1 binding above random expectation (Deniz et al., 2020). We found 203 several repeat families to be significantly enriched for STAG1 peaks, including those 204 within the DNA transposon and Retrotransposon classes, both known to form constitutive 205 heterochromatin. Specifically, STAG1 was enriched at SINE B2-Mm2, (previously shown 206 to be enriched at TAD borders (Dixon et al., 2012)) and B3 elements, LINE1 elements 207 (L1Tf, L1A), and several LTR families, two of which have been previously shown to be 208 associated with CTCF (LTR41, LTR55) (Schwalie et al., 2013) (Figures 2E and S2D). The 209 enrichment of Stag1 at non-coding and repetitive sequences has not been previously 210 described and points to a novel role for STAG1 in the regulation of repeats in ES cells.

\section{Stag1 regulates nuclear organization of heterochromatin.}

213 Since H3K9me3 is the defining histone modification of silent heterochromatin, we

214 assessed the impact of STAG1 loss and overexpression on H3K9me3 in ES cells. While 215 global levels of H3K9me3 were unchanged upon Stag1 KD (Figure S2E), 
216 immunofluorescence (IF) of H3K9me3 revealed changes to heterochromatin

217 organization. H3K9me3 foci displayed a greater variation in volume compared to

218 scrambled control treated cells, suggesting that Stag1 is required for proper H3K9me3

219 compaction (Figures 2F, G). We detected similarly variable changes to global chromatin

220 accessibility, as measured by DNase I digestion. In four out of six experiments, ES cells

221 treated with Stag1 siRNAs revealed a tendency towards increased accessibility, whereas

222 two experiments showed increased compaction (Figure 2H, S2F). On the other hand,

223 Dox-inducible STAG1 expression led to a dramatic condensation of H3K9me3 into large

224 nuclear puncta compared to non-induced cells (Figures 2I, J), where STAG1 could also

225 be seen to be colocalized with H3K9me3 in the condensate. This phenotype led us to

226 investigate whether STAG1 may have characteristics found in other proteins known to

227 play a role in heterochromatin phase separation(Larson et al., 2017). We used the

228 PONDR tool (Obradovic et al., 2003) to assess potential intrinsically disordered regions

229 (IDR) (Banani et al., 2017) within STAG1. STAG1 has an overall PONDR score of 0.4397,

230 and both the $\mathrm{N}$-and C-terminal divergent regions contain sequences with a high

231 propensity for intrinsic disorder (Figure $2 \mathrm{~K}$ ). Interestingly, these coincide with known

232 STAG1 domains, most notably the N-terminal AT-hook. Together our results uncover a

233 novel role for STAG1 in forming or maintaining heterochromatin structures in ES cells and

234 suggest that the terminal ends may play important roles therein.

236 Stag1 expression is highly regulated in ES cells.

237 STAG1 levels are highest in naïve 2i-grown and lower in FCS-grown ES cells, a culture 238 condition that supports a mix of naïve and primed cells (Figure S1B). This prompted us

239 to investigate whether STAG1 is regulated at the transcriptional level. To address this, 240 we employed a series of approaches to comprehensively characterize Stag1 mRNAs and 241 discovered widespread regulation of Stag1 transcription in ES cells. First, we used RACE 242 (Rapid Amplification of cDNA Ends) to characterize the starts and ends of Stag1 mRNAs. 243 Using 5' RACE, we uncovered four novel alternative transcription start sites (TSS) in ES 244 cells; one located 50kb upstream of the canonical Stag1 TSS (referred to as 'SATS', and 245 previously identified in (Feng et al., 2016)) (Figures 3A, D, S3A), one between canonical 
246 exon 1 and exon 2 (referred to as alternative exon 1 or altex1) (Figure 3D), one at exon

247 6, and one at exon 7 (Figures 3B, D, S3A, B (for increased exposure). Interestingly, the

248 novel TSS located at exon 7 (e7) was preceded by a sequence located in trans to the

249 Stag1 gene, carrying simple repeats and transcription factor binding sites (Figure S3C).

250 While the frequency of this alternative TSS was significantly lower than the other TSSs,

251 it was identified in multiple RACE replicates, indicating it may have important functions in

252 a subset of the ES population. We also discovered widespread alternative splicing in the

2535 ' region of Stag1, with particularly frequent skipping of exons 2 and $3(e 2 / 3 \Delta)$ and exon

$2545(e 5 \Delta)$ (Figures 3D, S3A). Using 3' RACE, we detected an early termination site in intron

25525 and inclusion of an alternative exon 22 introducing an early STOP codon, as well as

256 several 3'UTRs (Figures 3C, D, S3D).

257 Next, PCR- and Sanger sequencing-based clonal screening confirmed that the

258 newly discovered 5' and 3' ends represent true Stag1 transcript ends, validated the

259 existence of the e2/3 $\Delta$ and e5 $\Delta$ isoforms, and uncovered an isoform lacking exon 31

$260(\mathrm{e} 31 \Delta)$ (Figures 3D, S3E). To determine the complete sequences of the Stag1 transcript

261 isoforms and to use a non-PCR-based approach, we performed long-read PacBio Iso-

262 seq from 2i ES RNA. This confirmed the diversity of the Stag1 5' and 3'UTRs, the e31 $\Delta$

263 isoform, multiple TSSs, including SATS, and early termination events, including in i22 and

264 i25 (Figure S3F). Importantly, these transcripts all had polyA tails, in support of their

265 protein-coding potential. Finally, we validated and quantified the newly discovered

266 splicing events by calculating the frequency (percentage spliced in (PSI)) of exon splicing

267 in our and published RNA-seq data using VAST-tools, a previously developed 268 computational method (Tapial et al., 2017) (Figure 3E, Table S2). Together, these results

269 point to a previously unappreciated diversity of endogenous Stag1 transcripts in ES cells,

270 highlighting the importance of Stag1 regulation in stem cell populations.

272 The chromatin landscape reflects Stag1 transcriptional regulation.

273 Visual inspection of the genome topology around the Stag1 locus in our existing 2i ES

274 and neural stem (NS) cell Hi-C datasets (Barrington et al.) revealed that the STAG1 gene 275 undergoes significant 3-D reorganization as cells differentiate (Figure 3F). First, the entire 
276 STAG1 TAD switches from the active to the repressive compartment during 277 differentiation, in line with the decrease in Stag1 levels described above. Furthermore, 278 we observed several changes to the sub-TAD architecture which corresponded to the 279 newly discovered Stag1 TSSs and TTSs described above (Figure 3F, compare 'SA1 280 transcripts' track with Hi-C maps). We quantified these changes by designing site-specific 281 UMI-4C baits guided by the Hi-C topology. In naïve ES cells, the genomic region 282 containing the alternative SATS TSS has several Nanog binding sites and makes 283 numerous contacts with the Stag1 gene body (Figure 3F, 'Nanog bait 1'). Meanwhile, in

284 NS cells, the SATS TSS is no longer active and becomes isolated away from the STAG1 285 gene body due to the reinforcement of the TAD border at the canonical promoter of Stag1 286 (Figure 3F, 'CTCF bait'). In addition, a cluster of low-occupancy CTCF binding sites within 287 the Stag1 gene mark an ES-specific contact insulation point giving rise to a sub-TAD. We 288 note that the observed Stag1 early termination events align with these CTCF sites. These 289 results suggest that $3 \mathrm{D}$ chromatin topology may play a direct role in facilitating the 290 transcriptional output of Stag1.

\section{Multiple Stag1 protein isoforms are expressed in ES cells.}

293 Stag1 transcript diversity was intriguing because many of the events were either specific 294 to ES cells or enriched compared to MEFs and NSCs (Figure 3A, E, S3E) and further, 295 because the transcript variants are predicted to produce STAG1 protein isoforms with 296 distinct structural features and molecular weights (Figure 3D, G). For example, the 297 truncation of the $\mathrm{N}$ terminus (e2/3 $\Delta$, e5 $\Delta$, e6 TSS and e7 TSS), and thus loss of the AT 298 hook (amino acid 3-58), could impact STAG1 association with DNA. Meanwhile, C299 terminal truncated Stag1 isoforms (altex22, i25 end, e31 $\Delta$ ) could affect STAG1-cohesin 300 interactions. Interestingly, the evolutionarily conserved Stag-domain ('SCD', AA 296-381) 301 (Orgil et al., 2015), shown to play a role in CTCF interaction (Li et al., 2020), would be 302 retained in all the transcripts identified here. Importantly, these events would yield STAG1 303 isoforms lacking either the $\mathrm{N}$ - or $\mathrm{C}$-terminal disordered regions and could thus impact the 304 ability of STAG1 to form condensate-like structures (Figure 3H). 
Immunoprecipitation (IP) of endogenous STAG1 revealed multiple bands corresponding to the predicted molecular weights for several protein isoforms and identified by mass spectrometry to contain Stag1 peptides (Figure 3I and Table S3), whose levels were reduced between naïve and primed cells (Figure S3G) and sensitive to Stag1 KD, alongside the canonical, full-length isoform (Figure 3J). Treatment of

310 Stag1 ${ }^{\text {NG_FKBP }}$ ES cells with dTAG followed by Western blotting of chromatin-associated

311 proteins with an antibody to the v5 tag further confirmed the sensitivity of the isoforms to

312 dTAG-mediated degradation, validating the presence of N-terminally truncated STAG1

313 protein variants (Figure $3 \mathrm{~K}$ ). Overall, our results indicate that complex transcriptional

314 regulation gives rise to multiple Stag1 transcripts and protein isoforms with distinct

315 regulatory regions and coding potential, the majority of which are expressed specifically

316 in naïve ESCs. Our discovery of such naturally occurring STAG1 isoforms highlights the

317 importance of STAG1 in ES cells and offers a unique opportunity to define the ES-specific

318 functions of the divergent N- and C-terminal ends of STAG1 in the context of pluripotency

319 gene expression and heterochromatin regulation.

\section{Skewing the abundance of Stag1 isoforms promotes transitions between cell}

322 states.

323 To study the functional consequences of STAG1 isoform expression changes on ES cells,

324 we took advantage of our detailed understanding of Stag1 transcript diversity to design 325 custom siRNA pools to selectively target, or retain, specific isoforms (Figure 4A). 326 Alongside the siRNAs from Figure 1 (SmartPool, SP), we designed siRNAs to specifically 327 target the SATS 5'UTR (esiSATS), the 5' end (siSA1-5p) or the 3' end (siSA1-3p) of Stag1 328 mRNA (see Methods). We anticipated that the KD panels would not completely abolish 329 all Stag1 transcript variants, but rather change the relative proportions, in effect skewing 330 the levels of the $\mathrm{N}$ - and C-terminal ends of Stag1. 3p siRNAs were expected to 331 downregulate full-length and $\mathrm{N}$-term truncated isoforms and retain $\mathrm{C}$-term truncated 332 isoforms. Meanwhile $5 p$ siRNAs would specifically retain N-term truncated isoforms.

333 siRNAs to the 5p and 3p ends of Stag1 reduce full-length Stag1 mRNA and protein 334 with similar efficiency to SP KDs (Figures 4B, C, S4A), while esiSATS reduces Stag1 by 
$33550-60 \%$, indicating that the SATS TSS functions to enhance expression of Stag1 336 specifically in naïve ES cells. We confirmed that Stag1 isoform proportions were altered 337 upon siRNA treatment using RNA-seq, RACE and immunoprecipitation. RNA-seq reads

338 aligning to Stag1 in the different siRNA treatments were quantified to represent the 339 residual $\mathrm{N}$-terminal, middle and C-terminal read proportions (Figure 4D). Residual reads 340 in the SP and $3 p$ KDs aligned primarily to the N-terminus and were depleted from the C341 term. While the $5 p \mathrm{KD}$ had the least read retention in the $\mathrm{N}$-terminus, supporting the 342 expectation that residual transcripts in the $5 p \mathrm{KD}$ have full C-terminal ends (Figure 4D). 343 These results were further supported by quantifying specific splicing events from the KD 344 RNA-seq datasets using VAST-tools (Figure S4B). In parallel, RACE was used to 345 validate changes to the proportions of Stag1 isoforms. 5' RACE in ES cells treated with $3465 p$ siRNA revealed downregulation of full-length Stag1 transcript while several N-terminal 347 truncated isoforms were upregulated compared to untreated cells (Figures 4E, S3A). 348 Similarly, transcripts terminating at the canonical 3' end of Stag1 are strongly reduced in 349 the SP and 3p siRNA KD samples and to a lesser extent in the $5 p K D$, while the transcript 350 terminating in i25 is substantially enriched upon 3p KD (Figure 4E). Immunoprecipitation 351 of STAG1 using an antibody which recognizes the N-terminus in Stag $1^{\text {NG_FKBP }}$ ES cells 352 treated with dTAG reveals the enrichment of STAG1-Cterm $\triangle$ isoforms (Figure 4F, 353 arrows). Thus, the siRNA panel used here provide us with a powerful tool to modulate the 354 proportion of the divergent ends of STAG1 in ES cells and study their potential roles in 355 cell fate regulation.

357 The C-terminus of STAG1 has a specific role in maintenance of the naïve 358 pluripotent state.

359 We analyzed pluripotency gene expression in the different KDs using RT-qPCR and RNA360 seq. RT-qPCR results suggested that $5 p$ and $3 p$ KDs may have differential effects on 361 Nanog expression in serum-grown ES cells (Figure S4C). Namely, there was a consistent 362 tendency towards Nanog downregulation in 3p KD while 5p KD had little effect on Nanog. 
363 GSEA supported the differential effect of the SATS, 3p and 5p KDs on naïve and primed

364 pluripotency signatures. In support of STAG1 playing a role in pluripotency, reducing

365 Stag1 levels by targeting the ES-specific SATS promoter leads to downregulation of the 366 naïve pluripotency gene signature and upregulation of the primed signature (Figure 4G), 367 reminiscent of the phenotype from SP KD (Figure 1G). A similar, more prominent loss of 368 the naïve signature was observed in $3 p$ KD, while the opposite was true for $5 p$ KD cells 369 where the naïve signature was maintained (Figure 4G).

$370 \quad$ The distinct gene expression signatures of the $3 p$ and $5 p$ KDs are reflected in 371 differences in cellular phenotypes. Cells treated with $3 p$ siRNAs exhibited a further loss 372 of self-renewal potential, consistent with the loss of the naïve pluripotency signature, with $37320 \%$ of colonies exhibiting AP-staining compared to $30 \%$ of colonies in the SP KDs, and 374 reduction of the area occupied by AP+ colonies by 40-60\% (Figures 4H, S4D). This was 375 not evident in the $5 p \mathrm{KD}$, where the effect on self-renewal was similar to scrambled control 376 treated cells (Figures 4H, S4D). Interestingly, unlike siRNA to Stag1, esiSATS results in 377 a variable effect on self-renewal (ranging from between 5-35\% reduction in AP+ area) 378 (Figure 4H), likely because the SATS TSS is expressed in the most naïve cells of the 379 population, the frequency of which varies significantly between FCS populations. Our 380 results further confirm the importance of STAG1 in self-renewal and point to a specific 381 role for the C-terminal of Stag1 in the maintenance of the naïve pluripotent state.

The N-terminus of Stag1 regulates heterochromatin and conversion to totipotent 384 state.

385 Both the $\mathrm{N}$-term $\triangle$ and $\mathrm{C}$-term $\triangle \mathrm{STAG} 1$ isoforms lost prominent IDRs (Figure $3 \mathrm{H}$ ), thus we investigated the effect of these on heterochromatin structure. ES cells treated with $5 p$

387 siRNAs exhibited variable H3K9me3 foci volumes, similar to the effect of SP KD (Figure 388 2G), implicating the N-terminus in H3K9me3 condensation (Figures S5A, B). On the other 389 hand, H3K9me3 foci volumes in 3p KD cells were not significantly different from scr 390 control cells. DNase I digestion of chromatin further confirmed global changes to 391 chromatin accessibility upon 5p, but not 3p, KD whereby four of six experiments revealed 392 chromatin decompaction (Figure S5C). We built up on these results by generating ES 
393 cell lines expressing dox-inducible SA $1^{\mathrm{e} 5 \Delta-\mathrm{GFP}}$ or SA $1^{\mathrm{i} 25-\Delta \mathrm{C}}$-GFP, as representative of the

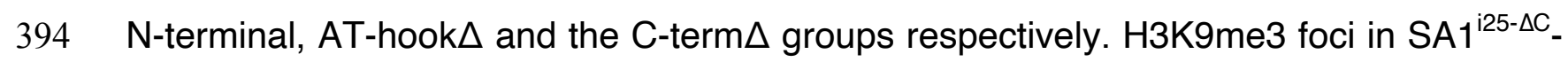

395 GFP-expressing cells revealed increased condensation compared to control cells, with a 396 similar effect as SA1 ${ }^{\mathrm{FL}}$-GFP. Meanwhile, the condensation of $\mathrm{H} 3 \mathrm{~K} 9 \mathrm{me} 3$ foci in $\mathrm{SA} 1^{\mathrm{e} 5 \Delta-}$ 397 GFP-expressing cells was significantly attenuated from SA1 ${ }^{\mathrm{FL}}$-GFP cells (Figures 5A, B).

398 Thus, while both the N- and C-termini of STAG1 play a role in heterochromatin structure, 399 loss of the basic N-terminus (which interacts with DNA via the AT-hook region(Bisht et 400 al., 2013)), significantly affects condensate structure, indicating its importance in 401 heterochromatin compaction.

Since STAG1 was bound to repeats, which play significant roles in ES cell fate determination, and are involved in heterochromatin regulation, we also profiled the 404 expression of LINE-1, IAPEz and MERVL elements in our KD panel. Surprisingly, MERVL elements were significantly derepressed in $5 p \mathrm{KD}$, but not in SP or $3 p \mathrm{KD}$ conditions (Figures 5C and S5D). The effect was specific to MERVL, we saw no significant change to the expression of LINE1-T or IAPEz (Figure 5C), despite the enrichment of STAG1 at L1T elements (Figure 2D). Re-activation of MERVL is a hallmark of a rare subpopulation of totipotent cells (termed two-cell-like, 2C-L) which spontaneously arise in ES cell cultures and exhibit unique molecular and transcriptional features including chromatin 411 decompaction, reminiscent of our 5p KD (Eckersley-Maslin et al., 2016; Ishiuchi et al., 412 2015; Macfarlan et al., 2012). Indeed, changes to MERVL expression in the 5p KD was 413 accompanied by increased expression of additional hallmark 2C-L genes and chimeric 414 transcripts (Dux, Gm6763, AW822073 and Gm4981) in serum-grown and 2i cells (Figures $4155 \mathrm{D}, \mathrm{S} 5 \mathrm{E})$. We note that the effect of $5 \mathrm{p} \mathrm{KD}$ on $2 \mathrm{C}-\mathrm{L}$ genes is modest in serum-grown ES 416 cells and significantly stronger in naïve ES cells. Notably, all 2C-L genes analyzed 417 remained unchanged in $3 p$ KD conditions with a modest but insignificant upregulation in 418 SP KD. Despite the modest but coordinated changes we observed by qRT-PCR of 2C-L 419 genes (Figure 5D), GSEA using a published 2C gene set (Percharde et al., 2018) 420 revealed a specific enrichment among the upregulated genes in $5 p$ KDs that was not 
421 observed in 3p KDs (Figure 5E, S5F). Together our results point to a specific role for the

$422 \mathrm{~N}$-terminus of STAG1 in totipotency regulation.

To investigate this further, we asked whether the loss of the N-terminus of STAG1

424 drives conversion of ES cells towards a totipotent $2 \mathrm{C}-\mathrm{L}$ state. We obtained ES cells

425 expressing a dox-inducible Dux-HA-expression construct together with a MERVL-linked

426 GFP reporter (Hendrickson et al., 2017) and used flow cytometry to measure the number

427 of GFP-positive cells in our different Stag1 KD conditions (Figures 5F, G). Chaf1 is a 428 chromatin accessibility factor previously shown to support conversion of ES cells towards 429 totipotency (Ishiuchi et al., 2015). In support of the upregulation of the 2C gene set in 5p 430 KD cells, we observed an 8-9\% increase in the proportion of GFP-positive cells in 5p KD 431 conditions compared to scramble treated controls, similar to the effect of Chaf1 KD 432 (Figures 5F, G). There was a modest increase in GFP+ cells upon SP KD and no effect 433 upon 3p KD. Chaf1 and 5p double KD had an additive effect on the proportion of GFP434 positive cells, suggesting that the two proteins function in complementary pathways for conversion towards totipotency.

\section{A 2C-specific Stag1 promoter.}

438 Our results point to the $\mathrm{N}$-terminus of Stag1 having a protective function in the conversion 439 of ES cells towards totipotency. Given the known role for increased chromatin 440 accessibility during conversion to 2C (Ishiuchi et al., 2015) and the importance of the N-

441 terminus in heterochromatin organization reported here, we propose that the Stag1 N442 terminus, and specifically the AT-hook within it, is involved in heterochromatin silencing 443 by forming or maintaining a condensed heterochromatin structure. This predicts that the 444 2C-L cells which spontaneously arise within the ES population could express Stag1N $\Delta$ 445 protein isoforms to support their preferred chromatin status and reinforce their cell state. 446 To formally address this, we induced DuxHA-expression in the MERVL-GFP ES cells and 447 performed 5' RACE on sorted GFP+ and GFP- cells (Figure 5H). We enriched several of 448 the previously identified N-term truncated Stag1 transcripts in the GFP+ population 
449 including e2/3 $\Delta$ and e5 $\Delta$ isoforms. Importantly, we also identified a transcript starting at 450 e7, similar to the one previously found in 5p KD ES cells (Figure 3B, S3C). Remarkably 451 however, the sequence preceding the TSS in e7 in Dux-induced cells was an MT2-

452 MERVL element, creating a chimeric, LTR-driven transcript akin to others specifically 453 expressed in the $2 \mathrm{C}-\mathrm{L}$ state (Figures $5 \mathrm{H}, \mathrm{I}$ ). Thus, the $2 \mathrm{C}-\mathrm{L}$ state selectively expresses 454 an N-term truncated Stag1 isoform which in turn supports the maintenance or emergence 455 of that state.

Stag1 regulates $2 \mathrm{C}$ fate via changes to nucleolar structure and function.

458 As ES cells preferentially expressing STAG1N $\Delta$ isoforms led to conversion towards 459 totipotent cell states and STAG1 is localised to the nucleolus and interacting with 460 Nucleolin, we asked whether the STAG1-induced 2C-L state could be explained by the 461 association of STAG1 with the Nucleolin/Trim28 complex known to derepress Dux targets 462 (Percharde et al., 2018). While STAG1 proteins directly interact with Nucleolin as well as 463 Trim28 (Figures 5J), Dux itself is weakly or variably deregulated in Stag1 KDs (Figure 464 5D). Similarly, while MERVL is robustly derepressed upon 5p KD (Figures 5C, F), Stag1 465 protein is not enriched at MERVL elements (Figure 2D), suggesting that the observed 466 effects are unlikely to be via Dux-mediated derepression of targets and may be indirect. 467 Thus, we investigated whether the Stag1-induced 2C-L state could be explained by 468 changes to nucleolar structure or function. In this context, we examined the consensus 469 sequence of the rDNA locus and note that there are several SINE elements located within 470 the intergenic spacer (IGS). Analysis of Stag1 ChIP-seq alignments to this region is 471 complicated by the repetitive nature of the region, however there was evidence of 472 possible Stag1 binding to the B3 elements within the IGS, suggesting that Stag1 may 473 directly support nucleolar structure and function (Figure S6B).

We explored this hypothesis by investigating the effect of Stag1 loss on rRNA 475 transcription. ES cells were pulsed with 5-ethynyl uridine (EU) which becomes actively 476 incorporated into nascent RNA and enables detection of newly synthesized RNA either 
477 spatially by immunofluorescence or globally by flow cytometry. Samples for 478 immunofluorescence were co-stained with an antibody to Nucleolin to quantify changes 479 in nascent rRNA transcription. Cells treated with scramble siRNA showed a distinct 480 nucleolar structure and the EU signal could be seen throughout the nucleus, with a strong 481 enrichment within the nucleolus as expected from rRNA expression (Figures 6A, B). A 482 significant reduction in nascent rRNA signal was observed in all KD conditions compared 483 to the si scr control. Interestingly, while the medians between the three siSA1 KDs were 484 not dramatically different, the effect of the $5 p$ KD on rRNA signal distribution was 485 significantly different from the $3 p \mathrm{KD}$, revealing different roles for the $\mathrm{N}$ and C-terminal 486 ends of Stag1 in nucleolar function. In parallel, we used flow cytometry to validate the 487 above and quantify the effect on global levels of transcription upon Stag1 loss. In support 488 of the immunofluorescence results, we observed a reduction in nascent transcription in 489 all siSA1 KDs compared to scrambled control (Figures 6C, D). SP and 5p KD reduced 490 nascent transcription by $39 \%$ and $47 \%$ respectively, the bulk of which is likely from the 491 observed change to rRNA expression. Meanwhile, cells treated with 3p siRNA exhibited 492 a 16\% reduction in global transcription compared to scrambled controls, further implying 493 that the $\mathrm{N}$ - and C-terminal ends of Stag1 likely target different pools of newly synthesized 494 transcripts.

Finally, given the changes to nascent rRNA transcription and the known role for translation in 2C-L state conversion (Eckersley-Maslin et al., 2016; Hung et al., 2013), we 497 measured effects on translation. Indeed, previous results showed a stronger effect of 498 Stag1 KD on Nanog protein compared to Nanog mRNA levels (Figures 1D, E). ES cells 499 were pulsed with L-homopropargylglycine (HPG), an amino acid analog of methionine 500 and flow cytometry was used to quantify the impact of Stag1 KD on global protein 501 synthesis. The proportion of cells that had reduced incorporation of HPG increased 502 significantly in the SP and 5p siRNA treated cells compared to scramble controls (32\% 503 and $35 \%$ of si Scr) (Figures 6E, F). We did observe a mild affect on global nascent 504 translation in 3p KD treated cells (16\% of si scr), although this was not significantly 505 different from scramble controls (Figures 6E, F). Overall, our work has uncovered a novel 
506 role for Stag1 in translation control and proposes that Stag1 may act directly at the rDNA

507 locus or via Nucleolin to influence the regulation of rRNA expression. To our knowledge,

508 a role for Stag1 in translation regulation has not been previously described and offers a

509 completely new perspective on how Stag1 impacts cell fate, moving beyond its known

510 roles in gene expression by regulating chromatin loops. 


\section{DISCUSSION}

512 Cell fate transitions during early development are accompanied by extensive

513 transcriptional and epigenetic reprogramming. In addition to changes in protein-coding 514 gene expression, repetitive sequences play an integral role in developmental 515 programmes (Jachowicz et al., 2017; Macfarlan et al., 2012; Percharde et al., 2018). 516 Repetitive sequences are spatially clustered into heterochromatin domains to facilitate 517 their regulation (Allshire and Madhani, 2018; Padeken and Heun, 2014). How cohesin 518 function, or Stag proteins contribute to heterochromatin or repeat regulation has not been 519 extensively studied in mammalian cells, despite the importance of both for cell identity.

$520 \quad$ While previous studies have implicated Stag proteins in cell fate decisions 521 (Cuadrado et al., 2019; Viny et al., 2019), they have primarily focused on the impact to 522 protein-coding gene regulation. By discovering a novel role for Stag1 in heterochromatin 523 structure, repetitive elements and translation control, we significantly expand our 524 understanding of Stag1 functions and thus deliver new insight into the mechanisms by 525 which Stag proteins and cohesin regulation impact cell identity and lead to disease. 526 Further, by comprehensively characterising naturally occurring Stag1 protein isoforms, 527 we identify distinct roles for the $\mathrm{N}$ - and C-termini of Stag1 which shed mechanistic light 528 on the reported distinct functions of the Stag paralogs (Cuadrado and Losada, 2020). For 529 example, the $\mathrm{N}$-terminal containing AT-hook of Stag1 represses heterochromatin 530 condensation and its loss leads to global changes in chromatin compaction and 531 reprogramming of ES cells towards totipotent $2 \mathrm{C}-\mathrm{L}$ cells. Our observation that the AT532 hook domain is required for heterochromatin compaction may explain the dominance of 533 Stag1 in stem cell populations since Stag2 does not have an AT-hook and 534 heterochromatin must be tightly regulated during early development.

535 We have characterized diverse transcription-regulatory events at the Stag1 locus 536 in stem cell populations giving rise to protein isoforms with distinct regulatory domains. 537 Importantly, this extensive Stag1 protein heterogeneity supports a continuum of cell 538 states within the population since experimentally induced imbalances in isoform 539 proportions skews cell fate probabilities. Using RACE in cells enriched for the $2 \mathrm{C}-\mathrm{L}$ fate, 
540 we find evidence for skewed expression of particular Stag1 isoforms, arguing that 541 individual ES cells may naturally predominantly express particular Stag1 protein isoforms.

542 Interestingly, the proportions of Stag1 isoforms likely originate in part from the stochastic 543 process of splicing (Fiszbein and Kornblihtt, 2017; Gabut et al., 2011; Salomonis et al., 544 2010), which is itself further randomized by the fluctuating chromatin landscape (Mateo 545 et al., 2019; Rodriguez et al., 2019), acting as a feedback mechanism for further Stag1 546 diversity. Thus, the naturally occurring Stag1 isoforms described here may act as intrinsic 547 sources of noise that both directly and indirectly support cellular plasticity.

We propose that a balance of Stag1 protein isoforms is required for variation in gene and repeat expression and thus, a continuum of cellular states. The $\mathrm{N}$-terminal containing AT-hook of Stag1 supports global chromatin compaction and heterochromatin condensation, suggesting that it plays an important role in clustering repetitive sequences into heterochromatin condensates for their regulation. Indeed, we observe dramatic changes to rRNA expression in $5 p \mathrm{KD}$ cells where isoforms lacking the $\mathrm{N}$-terminus are specifically retained. Moreover, we note that our live cell microscopy also revealed condensate-like structures within the nucleoplasm. It is possible that the C-terminus of Stag1 regulates euchromatin condensate formation to support pluripotency gene networks. Several lines of evidence support this. First, many of the genes that are

558 downregulated upon 3p KD are super-enhancer-associated genes which are known to 559 form condensate structures (Sabari et al., 2018; Whyte et al., 2013). Further, global 560 nascent transcription is reduced in 3p KD cells, although rRNA is not as affected as in the $5615 \mathrm{p} \mathrm{KD}$, suggesting that the C-term of Stag1 may have a role in regulating a different 562 subset of nascent transcripts. Thus, the Stag1 protein heterogeneity discovered here 563 provides the necessary fluctuations in the levels and composition of the Stag1 disordered 564 regions to impact the stability of both euchromatin and heterochromatin condensates, 565 thereby supporting plasticity within the population.

566 Stag1 knockout $\left(\operatorname{Stag} 1^{\Delta / \Delta}\right)$ ES cells give rise to mice which survive to E13.5 567 (Remeseiro et al., 2012b). At first this observation seems at odds with our report that 568 Stag1 is required for pluripotency. However, our observations may in fact explain why the 
569 Stag $1^{\Delta / \Delta}$ mouse model does not exhibit early embryonic lethality. In this model, only the 5705 ' region of Stag1 was targeted, meaning that the Stag1 isoforms lacking the N-terminus 571 may still be retained in the targeted ES cells. This is consistent with our results showing 572 that $5 p$ KD cells have not lost their ability to self-renew nor is their pluripotency gene 573 signature affected. It further suggests that changes to heterochromatin may exist in these 574 cells.

575 The role for Stag1 in heterochromatin structure described here may be quite 576 general, and the fact that Stag1 binds to HP1a and repetitive sequences known to form 577 constitutive heterochromatin suggests that this is true. Indeed, the AT-hook domain of 578 Stag1 has been shown to be important for telomere cohesion (Bisht et al., 2013). Here 579 we have specifically uncovered a role for Stag1 in nucleolar structure and function in stem 580 cells. Transcriptionally inactive rDNA arrays are associated with the periphery of the 581 nucleolus and accumulate marks of constitutive heterochromatin while actively 582 transcribed rDNA loci are looped inside the nucleolus (Padeken and Heun, 2014). We 583 observe Stag1 at both the interior and periphery, suggesting that it may be involved in 584 multiple aspects of rDNA and nucleolar regulation. Stag1 is enriched at SINE elements 585 and we note that the intergenic spacer region of the rDNA consensus contains multiple 586 B3 and B2_Mm2 sequences, strongly suggesting that the changes in nascent rRNA 587 transcription are direct effects of Stag1 loss and implicates Stag1 in the formation or the 588 maintenance of the nucleolus. Indeed, CTCF has previously been implicated in nucleolar 589 structure by tethering insulators to the periphery (Yusufzai et al., 2004). As well as 590 impacting global translation, the change to nucleolar structure may also indirectly support 591 the emergence of the $2 \mathrm{C}$ state by destabilizing complexes such as Nucleolin/Trim28 592 which are required for the derepression of repeat elements (Percharde et al., 2018).

593 Finally, a role for Stag proteins or cohesin in translation regulation has, to our 594 knowledge, not been described before despite the fact that translation has important roles 595 in development (Buszczak et al., 2014). How Stag1 contributes to translation in ES cells 596 and whether it plays similar roles in other stem or progenitor populations are important 597 future questions. Our results offer new perspectives on how Stag proteins and cohesin 598 regulation contribute to cell identity during development and in disease. 


\section{Acknowledgments}

600 This work would not be possible without the support of a Senior Research Fellowship 601 from the Wellcome Trust awarded to S.H. (106985/Z/15/Z). We would like to thank Sally 602 Lowell and Mattias Malaguti for advice throughout the project. We are grateful to the 603 members of the Hadjur lab for critical discussions and reading of the manuscript. We 604 thank M. Irima for help with VAST-tools pipelines; B. Cairns for the inducible Dux-HA, 605 MERVL-GFP cell line; W.Reik for a second MERVL-reporter ES cell line; H. Rowe for 606 advice on 2C-L cells and J. Vaquerizas for advice on repeat expression analysis. Thank 607 you to Y. Guo and J. Manji in the Cancer Institute CRUK Centre FACS and Imaging core 608 facilities for their invaluable assistance.

\section{Author Contributions}

611 D.P. and S.H. conceived the project. D.P. designed and performed all the experiments 612 on ES cells with assistance from S.W. S.W. performed all protein analysis, generated the 613 SA1-NG-FKBP ES cell line, performed the Spinning Disk microscopy and helped with the

614 siRNA knockdown experiments. W.V. performed all bioinformatic analyses with the 615 exception of the Stag1 enrichments at repeat elements, which was done by M.B. P.D. 616 and S.P. provided advice on CRISPR targeting. D.P. and S.H. formatted all figures and 617 wrote the manuscript with input from all authors.

\section{Declaration of Interests}

620 The authors declare no competing interests. 


\section{Figure legends}

\section{Figure 1. STAG1 is required for pluripotency.}

623 (A) Log2 fold change of pluripotency factors and cohesin subunit gene expression 624 assessed by qRT-PCR during embryonic stem cell (ES) differentiation towards Epiblast625 like (EpiLC) cells. Multiple primer pairs were used for SA1 and SA2 mRNA. Data are 626 derived from two biological replicates.

627 (B) Whole cell protein extracts (WCL) from serum-grown (FCS) or naïve (2i) ES cells, 628 EpiLC and mouse embryonic fibroblasts (MEF) and analyzed by western blot (WB) for 629 levels of SA1, SA2 and Smc3.

630 (C) WB analysis of SA1 levels in WCL, cytoplasmic and chromatin fractions upon 631 treatment with scrambled siRNAs (siScr) or SmartPool SA1 siRNAs (siSA1) for 24hrs in 632 2i ES cells. Tubulin (Tub) and H3 serve as fractionation and loading controls.

633 (D) Relative expression of Nanog mRNA by qRT-PCR in 2i- (left panel, $\mathrm{n}=19$ ) or FCS634 grown (right panel, $n=20$ ) ES cells after no (UT), si scr or si SA1 treatment. Whiskers and 635 boxes indicate all and $50 \%$ of values respectively. Central line represents the median. 636 Asterisks indicate a statistically significant difference as assessed using 2-tailed T-test. * $637 p<0.05,{ }^{* *} p<0.005$, n.s., not significant.

638 (E) Mean Fluorescence Intensity (MFI) of Nanog protein assessed by 639 Immunofluorescence in $2 \mathrm{i}$ ES cells treated with si scr, a second siRNA control to 640 Luciferase (esi Luc) and si SA1. Cells were stained for Nanog, SA1 and counterstained 641 with DAPI. Quantifications and statistical analysis were done as above. Each treatment 642 was repeated a minimum of two times ( $n>100 /$ condition). ${ }^{* * * *} p<0.0005$.

643 (F) Volcano plot displaying the statistical significance (-log2 $p$-value) versus magnitude of 644 change (log2 fold change) from RNA-sequencing data produced in FCS ES cells treated 645 with si scr or siSA1 for $24 \mathrm{hrs}(\mathrm{n}=3)$. Vertical blue dashed lines represent changes of 2646 fold. Selected genes associated with pluripotency and differentiation have been 647 highlighted.

648 (G) Enrichment score (ES) plots from Gene Set Enrichment analysis (GSEA) using 649 curated Naïve or Primed gene sets (see Methods). Negative and positive normalized 650 (NES) values point to the gene set being over-represented in the top most down- or up651 regulated genes in SA1 KD ES cells, respectively. Vertical bars refer to individual genes 652 in the gene set and their position reflects the contribution of each gene to the NES. 
$653(\mathrm{H})$ Area occupied by AP+ colonies in ES cells treated with si scr and si SA1 from three

654 independent biological replicates where $n>50$ colonies/condition were counted.

655 (I) CRISPR/Cas9 was used to knock-in a NeonGreen-v5-FKBP tag on both alleles of 656 endogenous Stag1 at the C-terminus (SA1 ${ }^{\text {NG-FKBP }}$ ). The resultant Stag1 protein is $42 \mathrm{kDa}$ 657 larger. Shown are known features of SA1 including the N-terminal AT-hook (AT) and the 658 stromalin conserved domain (SCD). WB analysis of SA1 levels in a targeted ES clone 659 after treatment with DMSO-only or dTAG for 16 hrs. Tubulin (Tub) serves as a loading 660 control.

661 (J) Analysis of the area of AP+ colonies as above in wildtype ES and in a SA1 ${ }^{\text {NG-FKBP }}$ ES 662 clone treated with DMSO-only or dTAG for $16 \mathrm{hrs}$. Data is represented as mean \pm SEM 663 of three independent experiments and relative to the DMSO control.

664 See also Figure S1.

Figure 2. STAG1 associates with AT-rich heterochromatin.

(A) Live-cell Spinning Disk confocal images of three SA $1^{\text {NG-FKBP }}$ cells counterstained with Hoechst. Arrows indicate notable regions of overlap of SA1 and Hoechst, including inside

669 the nucleolus and at Hoechst-dense foci (top cell), and at the nucleolar periphery (bottom 670 cells).

671 (B) Mean Intensity of SA1-NeonGreen signal from (A) within the whole nucleus or 672 Hoechst-dense foci as identified using Imaris in the SA1 ${ }^{\text {NG-FKBP }}$ clone treated with DMSO 673 or dTAG. $n=270$ cells/condition.

674 (C) co-Immunoprecipitation of endogenous SA1 with Smc3, HP1a and Nucleolin in ES 675 cells.

676 (D) Percentage of SA1 peaks (unique reads) at promoters, exons, transposable elements 677 introns and intergenic sequences.

678 (E) STAG1 ChIP-seq data (unique and multimapping reads) aligned to full-length Repeat 679 elements of the indicated SINE, LINE and LTR families.

680 (F) Confocal images of Immunofluorescence (IF) to SA1 and H3K9me3 in siscr or siSA1 681 treated ES cells, counterstained with DAPI. 
682 (G) Imaris quantification of the volume of H3K9me3 foci from (F). Box plots and statistical

683 analysis were done as above. Each treatment was repeated twice ( $n>100 /$ condition). $684 \mathrm{p}<0.05$.

$685(\mathrm{H})$ Global chromatin accessibility as detected by DNase I digestion of genomic DNA at 686 different concentrations from 200,000 cells/condition in siScr or siSA1 ES cells.

687 (I) Confocal images of IF to GFP and H3K9me3 in ES cells expressing full-length SA1 688 tagged with GFP (SA1-FL), counterstained with DAPI.

689 (J) Imaris quantification of the volume of H3K9me3 foci from (I). Box plots and statistical 690 analysis were done as above. $n>50 /$ condition. $p<0.0005$.

691 (K) PONDR (Predictor of Natural Disordered Regions) analysis of SA1 protein using VSL2 692 predictor at http://www.pondr.com showing consecutive stretches of disordered regions 693 corresponding to the N-and C-terminus of Stag1.

694 See also Figure S2.

695

Figure 3. Diverse Transcription-Regulatory Control of Stag1 in ES cells.

697 (A, B) 5' Rapid Amplification of cDNA ends (RACE) for SA1 in ES and EpiLC cells. Arrows 698 indicate bands which were cloned and sequenced. In A, red star indicates SATS TSS and 699 red arrow indicates canonical TSS. In B: red indicates full length Stag1 with both SATS 700 and can TSSs; dark blue indicates alternatively spliced variants, skipping of various exons 701 in 5' region; light blue indicates the TSSs at e6, e7.

702 (C) 3' RACE for SA1 in ES cells. Arrows indicate bands which were cloned and 703 sequenced. Red indicates canonical full-length end; green indicates end in i25.

704 (D) Top, schematic of the Stag1 gene annotation in mm10 and the identified TSS and 705 TTSs from RACE indicated. Bottom, aligned sequence clones from the PCR mini-screen 706 and their predicted impact on the SA1 protein, right. Green arrows and red bars within the 707 transcripts indicate start of the coding sequence and the TTS respectively. Shown also 708 are the regions which code for the AT hook and SCD domains.

709 (E) Percent Spliced In (PSI) calculations based on VAST-Tools analysis of RNA-seq from 710 multiple 2i (blue) and FCS (red) datasets (see Methods for details of libraries). Data are 711 shown relative to Neural Stem cell (NSC) frequencies to highlight the events that are ES712 specific. 
713 (F) Genome topology at the Stag1 locus. Hi-C contact maps in ES (2i) and NS cells of

714 the $900 \mathrm{~kb}$ region on chromosome 9 containing the Stag1 topologically associated domain

715 (TAD). TADs are denoted with a vertical line and as repressed (orange) or active (blue).

716 Shown also are tracks for Genes, Nanog and CTCF ChIP-seq as well as a track indicating

717 the directionality of CTCF binding sites (red, forward; blue, reverse). Aligned to the Gene

718 track are also the SA1 transcripts discovered above where red represents the

719 untranslated regions and blue the coding body. UMI-4C-seq viewpoints (asterisks on the

720 ChIP tracks) are positioned to the leftmost CTCF site ('CTCF bait') and to the Nanog site

$72140 \mathrm{~kb}$ upstream of the Stag1 canonical TSS ('Nanog bait'). For each bait, UMI information

722 for each cell type is shown as well as the comparative plots where red represents an

723 enrichment of contacts in ES compared to NS.

724 (G) Top, cartoon depicting functional domains within Stag1 protein, including the AT-hook

725 (aa 3-58); Stromalin conserved domain (SCD, aa 296-381) and the C-terminus. Bottom,

726 the predicted Stag1 protein isoforms based on transcript analysis with estimated sizes for

727 each isoform. Purple boxes in the $105 \mathrm{kDa}$ and $90 \mathrm{kDa}$ isoforms represent retained introns.

728 (H) PONDR tracks as before shown for the N-terminal truncated (top) and C-terminal 729 truncated (bottom) transcripts.

730 (I) Chromatin immunoprecipitation of SA1 from ES cells.

731 (J) WB analysis of SA1 isoforms in chromatin fractions from ES cells treated with siscr 732 and siSA1. H3 serves as a fraction and loading control.

733 (K) Chromatin immunoprecipitation for the v5 tag in SA1 ${ }^{\text {NG-FKBP }}$ ES cells treated with 734 DMSO-only or dTAG. Note, SA1 bands now run 42kDa higher due to the addition of the 735 tag.

736 See also Figure S3, Table S1 and Table S2.

Figure 4. Fluctuations in the levels of the Stag1 isoforms skews cell fates.

739 (A) Schematic of the siRNA pools used in this study. esiRNA SATS represents 740 'enzymatically-prepared' siRNAs (see Methods).

741 (B) Relative expression of SA1 mRNA by qRT-PCR in FCS ES cells after no treatment 742 (UT), or upon si scr, si SA1 SP, si 3p, si 5p or esi SATS treatment. Data is represented 743 as mean $\pm \mathrm{SEM}, \mathrm{n}=3$. * $\mathrm{p}<0.05$ 
744 (C) WB analysis of SA1 levels in FCS ES WCL upon treatment with the same siRNA 745 panel from (B). Tubulin serves as a loading control.

746 (D) RNA-seq reads (as transcripts per million, TPM) aligning to sectioned Stag1 in 747 datasets from the various siRNA pools and presented as relative to untreated ES RNA748 seq. N-terminal reads include SATS and exons 1-8, Mid reads are from exons 12-19 and 749 C-terminal reads include exons 20-25 and exons 26-34.

750 (E) Left, 5' and Right, 3' RACE for SA1 in ES cells treated with the siRNA panels. Arrows 751 indicate bands which were cloned and sequenced and colour-coded as before.

752 (F) Chromatin immunoprecipitation using an N-terminal Stag1 antibody in SA1 ${ }^{\text {NG-FKBP }}$ ES 753 cells treated with DMSO-only or dTAG for $16 \mathrm{hrs}$. Green arrow indicates residual C754 terminal truncated Stag1 isoforms.

755 (G) Enrichment score (ES) plots from GSEA using Naïve or Primed gene sets as in Figure $7561 \mathrm{G}$ and RNA-seq data from the different siRNA treated ES cell samples.

$757(\mathrm{H})$ Area occupied by AP+ colonies in ES cells treated with the siRNA panel from three 758 independent biological replicates. $n>50$ colonies/condition were counted.

759 See also Figure S4.

Figure 5. Stag1 $\mathrm{N}$-terminus represses heterochromatin and promotes transition 762 towards totipotency.

763 (A) Confocal images of IF to GFP and H3K9me3 in ES cells expressing SA1-FL-GFP, 764 SA1-exon5 $\Delta$-GFP or SA1-Cterm $\Delta$-GFP. Nuclei were counterstained with DAPI.

765 (B) Imaris quantification of the volume of $\mathrm{H} 3 \mathrm{~K} 9 \mathrm{me} 3$ foci per cell from (A). Box plots and 766 statistical analysis were done as before. $n>50 /$ condition. ${ }^{* *} p<0.005,{ }^{* * * *} p<0.0005$.

767 (C, D) Relative expression of (C) repeat elements; MERVL, LINE1-T and IAPEz RNA 768 ( $n=8$ biological replicates each) and (D) 2C-L genes; Gm6763 $(n=6)$ and Dux $(n=5)$ by 769 qRT-PCR in FCS ES cells after treatment with the siRNA panel. Boxes and whiskers as 770 before. ${ }^{*} p<0.05$, n.s, not significant as per 2-tailed T-test. NB. The $p$-value for Gm6763 771 expression in $5 p$ KD vs UT $=0.07$.

772 (E) Enrichment score (ES) plots from GSEA using a published 2C-L gene set (Methods) 773 and RNA-seq data from the $3 p$ and $5 p$ siRNA treated ES cell samples. 
774 (F) Representative FACS analysis of the proportion of ES cells expressing a MERVL-

775 GFP reporter in the different siRNA treated cells and including siRNA to Chaf1 as a 776 positive control. Percentage of MERVL-GFP+ cells based on Flo-Jo analysis is shown in 777 red.

778 (G) Proportion of MERVL-GFP+ cells in the different siRNA conditions relative to the 779 siChaf1 positive control. Data is represented as mean \pm SEM of four independent 780 experiments. ${ }^{*} \mathrm{p}<0.05,{ }^{\star \star} \mathrm{p}<0.005$, n.s, not significant as per 2 -tailed T-test.

781 (H) 5' RACE for SA1 in Dux-HA, MERVL-GFP ES cells sorted for GFP+ cells. Arrows 782 indicate bands which were cloned and sequenced and colour-coded as before.

783 (I) Sequence of the 5'RACE product identifying a novel Stag1 TSS with direct splicing of 784 exon7 to MT2_MERVL element.

785 (J) Co-Immunoprecipitation of SA1 with Nucleolin and Trim28 in ES cells.

786 See also Figure S5.

Figure 6. rRNA expression and nascent translation upon Stag1 loss.

789 (A) Confocal images of IF to Nucleolin ( $\mathrm{Ncl}$ ) and Nascent RNA in ES cells treated with the 790 siRNA panel. Nuclei were counterstained with DAPI. Note the accumulation of nascent 791 RNA within the nucleolus.

792 (B) Imaris quantification from (A) of the mean intensity of nascent RNA (EU-488) within 793 the nucleoli, as defined by Nucleolin signal. Box plots and statistical analysis were done 794 as before. Data are from two biological replicates, $n>50 /$ condition, except for siSA1 5p 795 where $n>35 .{ }^{* *} p<0.005,{ }^{* * *} p<0.0005$ as per 2 -tailed T-test.

796 (C, D) Global analysis of Nascent transcription by measuring EU-488 incorporation using 797 Flow cytometry. (C) representative Flo-Jo analysis of EU incorporation in ES cells treated 798 with the siRNA KD panel. (D) Quantification of the change in EU incorporation relative to 799 si Scr treated cells. Data are from two biological replicates ${ }^{*} p<0.05,{ }^{* *} p<0.005$ as per 2800 tailed T-test.

801 (E, F) Global analysis of Nascent translation by measuring HPG-597 incorporation using 802 Flow cytometry. (E) Representative Flo-Jo analysis of HPG incorporation in ES cells 803 treated with the siRNA KD panel. (F) Quantification of the change in EU incorporation 
bioRxiv preprint doi: https://doi.org/10.1101/2021.02 14.429938; this version posted February 16, 2021. The copyright holder for this preprint

(which was not certified by peer review) is the author/funder, who has granted bioRxiv a license to display the preprint in perpetuity. It is made available under aCC-BY 4.0 International license.

804 relative to si Scr treated cells. Data are from four biological replicates ${ }^{*} \mathrm{p}<0.05,{ }^{* *} \mathrm{p}<0.005$

805 as per 2-tailed T-test.

806 See also Figure S6.

807 


\section{METHODS}

809 Embryonic stem cell culture and siRNA-mediated knockdown.

810 Male mouse E14 embryonic stem (ES) cells were cultured in serum (FCS) or naïve (2i) conditions.

811 Serum-cultured cells were grown on $0.1 \%$ gelatin-coated plates in GMEM, 10\% FCS (Sigma), 812 NEAA, Na Pyruvate, $0.1 \mathrm{mM}$ BMercaptoethanol (BMe), Glutamax, and freshly added LIF

813 (1:10,000). 2i-cultured cells were grown on plates coated with Fibronectin, in

814 DMEM:F12/Neurobasal 1:1, KnockOut Serum Replacement, N2, B27, Glutamax, $1 \mu \mathrm{M}$

815 PD0325901, 3 $\mu \mathrm{M}$ CHIR9902, $0.1 \mathrm{mM}$ BMe, and freshly added LIF as above. DuxHA/MERVL-

816 GFP cells were cultured in $2 \mathrm{i}$ conditions. siRNAs were purchased from Horizon Discovery

817 (previously Dharmacon) or Sigma (for 'enzymatically-derived' esiRNAs). siRNA knockdowns

818 (KDs) were performed for 24hr with the exception of those in Figure 5 which were performed for

819 72hr. Knockdowns were performed in 6-well plates where 200,000 cells were seeded for $72 \mathrm{hr}$

$820 \mathrm{KDs}$, and 400,000 for $24 \mathrm{hr}$ KD. 50pmol siRNAs were transfected using RNAiMax Lipofectamine

821 at the time of seeding, and after $48 \mathrm{hrs}$ for $72 \mathrm{hr}$ timepoints. Two siRNA controls were used,

822 scrambled (scr) was D-001810-10 and Luciferase (esiLuc) control purchased from Sigma. siSA1

823 'SmartPool' (SP) was derived from equimolar ratios of commercial siRNAs (D-041989-02, -04, -

824 05, -06, -07, -08). siSA1 $5 p$ was a custom Duplex siRNA sequence

825 (AGGAGCAGGUCGUGGAAGAUU). siSA1 3p was derived from equimolar ratios of commercial

826 siRNAs J-041989-05, -07, -08. esiRNA to SATS was purchased from Sigma as a custom-made

827 product to the entire SATS 5'UTR (mm10 chr9:100,597,794-100,598,109).

829 qRT-PCR analysis

830 Total RNA was isolated using Monarch RNA prep kit (NEB). Reverse transcription was performed 831 on $0.5 \mu \mathrm{g}$ DNase-treated total RNA using Lunascript RT (NEB) in $20 \mu \mathrm{l}$ reactions. qPCR was 832 performed using $2 x$ SensiFAST SYBR No-ROX kit (Bioline) in $20 \mu$ reactions using $1 \mu$ l of RT 833 reaction as input and $0.4 \mu \mathrm{M}$ each primer.

\section{Alkaline Phosphatase (AP) assay and quantification}

836 Cells were seeded in 6 well plates and transfected with siRNAs at the time of plating as above.

837 After $24 \mathrm{hrs}$, cells were collected for RNA isolation and KD efficiency analyzed by qRT-PCR. Cells

838 from each condition were counted and 1,000 cells per well seeded into a new 6-well plate. Cells 839 were re-transfected after 48 hrs using 5 pmol of siRNAs. Cells were fed every day. Four days 
840 after seeding cells at clonal density, the cells were assayed for alkaline phosphatase (AP)

841 expression using StemTAG Alkaline Phosphatase staining kit (Cell Biolabs CBA-300). AP stained

842 cells were imaged in 6-well plates using a M7000 Imaging System (Zeiss) with a 4X objective and

843 a Trans-illumination brightfield light source. For quantification, AP-high and AP-low colonies from

844 each condition were counted. Area occupied by AP-high colonies was also measured using

845 ImageJ, and plotted as fraction of total area of all colonies.

847 RACE (Rapid Amplification of cDNA Ends) and PCR mini screen

848 RACE was performed using GeneRacer kit (RLM RACE, Invitrogen L1500). $2 \mu \mathrm{g}$ of total RNA was

849 used as input. Final products were amplified by nested PCR, using Kapa 2x MasterMix. First PCR

850 was done in a $50 \mu \mathrm{l}$ reaction using $1 \mu \mathrm{l}$ RT as input, 25 cycles. DNA was purified using Qiagen

851 PCR Purification kit, and nested PCR was performed on a tenth of the first PCR for 30 cycles.

852 Viewpoint for 5'RACE was in exon 2 (Fig 3A) or exon 8 (Fig 3B) of Stag1. Viewpoint for 3'RACE

853 was in exon 23 (Fig 3C). RACE primer details can be found in Table S3. PCR products were

854 excised from the gel, A-tailed using Klenow exo- (NEB) and cloned into pCR4-TOPO vector

855 (Invitrogen). At least three clones were sequenced per PCR product. For the PCR Mini-Screen,

856 forward primers at either SATS or canonical 5' UTR were used with reverse primers either at the

857 end of Stag1 canonical coding sequence, or at the end of coding sequence in intron 25 (see Table

858 S3). PCR was performed using Kapa 2x MasterMix. DNA was excised from the gel, A tailed, and

859 cloned into pCR4-TOPO. At least six clones per PCR product were Sanger-sequenced.

860 Sequences from the PCR Mini-screen were aligned using Minimap2 (2.14-r884) in 'splice' mode

861 to ensure long read splice alignment (Fig 3D and S3A).

\section{PONDR Predictions}

864 Internally disordered regions were predicted using VSL2 predictor at http://www.pondr.com.

\section{CRISPR-Mediated Stag1 Knock-in Cell Line Generation}

867 The guide RNA targeting Stag1 3' terminal coding region was designed using Tagin Software

868 (http://tagin.stembio.org) and purchased from IDT. Lyophilised gRNA was rehydrated in RNA

869 duplex buffer $(100 \mu \mathrm{M})$. The single stranded oligodeoxynucleotides (ssODN) encoding $870 \mathrm{mNeonGreen}(\mathrm{mNG})-\mathrm{V} 5-\mathrm{FKBP} 12^{\mathrm{F} 36 \mathrm{~V}}$ and the left and right homology arms was designed using 871 the software tool ChopChop (https://chopchop.cbu.uib.no) and purchased as a High-Copy Amp872 resistant plasmid from Twist Bioscience. $2.2 \mu \mathrm{lgRNA}(100 \mu \mathrm{M})$ was mixed with $2.2 \mu \mathrm{l}$ tracrRNA 
873 ATTO 550nm (IDT) and annealed together. The RNA duplex was then incubated with 20 $\mu$ g S.p

874 Cas9 Nuclease V3 (IDT) for 10min at room temperature and stored on ice prior to transfection.

875 Linearised $\mathrm{KI}$ sequence was mixed with $100 \%$ DMSO and denatured at $95^{\circ} \mathrm{C}$ for $5 \mathrm{~min}$. The ssODN was plunged immediately into ice. The RNP complex was mixed with confluent 2i-grown ES cells re-suspended in P3 transfection buffer (Lonza) before being transferred to an electroporation microcuvette well (Lonza). Transfection was performed using a 4D Amaxa electroporator. Post-nucleofection, the cells were seeded into a fibronectin-coated 6 well plate with fresh ES media. The media was changed daily for four days before being expanded into a T75 flask. Confluent ES cells were FACS sorted for GFP+ population (BD FACS Aria Fusion Cell Sorter) and sparsely seeded into $10 \mathrm{~cm}$ plates. Clones were manually picked into 96 well plates and expanded for selection by v5 IF, genotyping and Sanger sequencing.

\section{Dox-inducible Stag1-GFP isoform cell lines}

886 Stag1 isoforms were cloned into pCW57.1 vector (Addgene 41393), modified using Gibson 887 assembly to include an EGFP tag at the 3'end of the Gateway cassette, using Gateway recombination by LR clonase. For primers used to clone the isoforms see Supplementary Table S3. Plasmids were transfected into 2i-grown ES cells using Lipofectamine 3000 and cells grown in Puromycin-supplemented media $(1 \mu \mathrm{g} / \mathrm{ml})$ for ten days to make stable lines. Isoform expression was induced using $2 \mu \mathrm{g} / \mathrm{ml}$ Doxycycline for $24 \mathrm{hrs}$, and the population enriched for GFP-positive cells using FACS. For IF experiments, isoforms were induced by adding Dox for 48 hours.

Protein Lysates, Fractionations and Western blotting.

895 Whole cell lysates (WCL) were collected by lysis in RIPA buffer (150mM NaCl, $1 \%$ NP-40 896 detergent, $0.5 \%$ Sodium Deoxycholate, 0.1\% SDS, 25mM Tris- $\mathrm{HCl} \mathrm{pH} \mathrm{7.4,1mM} \mathrm{DTT)} \mathrm{and}$ 897 sonicated at $4^{\circ} \mathrm{C}$ for $\times 530$ second cycles using Diagenode Bioruptor. Insoluble material was 898 pelleted and the supernatant lysate was quantified using BSA Assay (Thermo Scientific). For 899 cellular fractionations, a cellular ratio of $5 \times 10^{6}$ cells $/ 80 \mu$ l buffer was maintained throughout the 900 protocol. Cells were re-suspended in Cell Membrane Lysis Buffer (0.1\% Triton X, 10mM HEPES $901 \mathrm{pH} 7.9,10 \mathrm{mM} \mathrm{KCl}, 1.5 \mathrm{mM} \mathrm{MgCl} 2,0.34 \mathrm{M}$ sucrose, $10 \%$ glycerol, $1 \mathrm{mM}$ DTT), incubated on ice for $9025 \mathrm{~min}$ and centrifuged for $5 \mathrm{~min}$ at 3700rpm to collect the cytoplasmic sample. The pellet was 903 washed and then re-suspended in Nuclear Lysis Buffer (3mM EDTA, 0.2mM EGTA, 1mM DTT) 904 and incubated on ice for $1 \mathrm{hr}$. Nuclear lysis was aided by sonication with a handheld homogeniser 905 (VWR) for $10 \mathrm{sec}$ at $10 \mathrm{~min}$ intervals. The nucleoplasmic supernatant and chromatin pellet were 
separated by centrifugation at $9000 \mathrm{rpm}$ for $10 \mathrm{~min}$ at $4^{\circ} \mathrm{C}$. The chromatin pellet was re-suspended in $160 \mu \mathrm{l} 2 \mathrm{X}$ Laemmli Buffer (Bio-Rad). Equal volumes of each fraction were used for Western

908 Blotting (WB). Cytoplasmic and nucleoplasmic protein samples were diluted in 2X Laemmli Buffer 909 and boiled for $5 \mathrm{~min}$ at $95^{\circ} \mathrm{C}$, then loaded on a $4-20 \%$ SDS-PAGE gel (Bio-rad) or a $3-8 \%$ Tris 910 Acetate gel (Invitrogen). Proteins were wet transferred onto a PDVF membrane (Millipore) and 911 assessed for successful transfer with Ponceau Red (Sigma). The membrane was blocked with $91210 \%$ milk and incubated with primary antibodies in $1 \%$ milk, $0.1 \%$ Tween-PBS overnight at $4{ }^{\circ} \mathrm{C}$.

913 Membranes were imaged with SuperSignal West Femto Maximum Sensitivity (Thermo) on an 914 ImageQuant.

916 Chromatin Co-Immunoprecipitation (co-IP)

917 Cells were re-suspended in $0.1 \%$ NP-40-PBS $\left(1 \mathrm{ml} / 1 \times 10^{7}\right.$ cells) with $1 \mathrm{X}$ Protease Inhibitors

918 (Roche) and $1 \mathrm{mM} \mathrm{DTT}$, and centrifuged at $1500 \mathrm{rpm}$ for $2 \mathrm{~min}$ at $4^{\circ} \mathrm{C}$. The pellet was re-suspended 919 in Nuclear Lysis Buffer (3mM EDTA, 0.2mM EGTA, 1X Protease Inhibitors, 1mM DTT), vortexed 920 for $30 \mathrm{sec}$ before being incubated on a rotator for $30 \mathrm{~min}$ at $4^{\circ} \mathrm{C}$ and centrifuged at $6500 \mathrm{~g}$ for $5 \mathrm{~min}$ 921 at $4^{\circ} \mathrm{C}$ to isolate the glassy chromatin pellet. This was re-suspended in High Salt Chromatin 922 Solubilisation Buffer (50mM Tris- $\mathrm{HCl}$ pH 7.5, 1.5mM MgCl2, 300mM KCl, 20\% glycerol, $1 \mathrm{mM}$ 923 EDTA, 0.1\% NP-40, 1mM Pefabloc, 1X Protease Inhibitors, 1mM DTT) with Benzonase (Sigma) $924\left(6 \mathrm{U} / 1 \times 10^{7}\right)$ and incubated on rotator for $30 \mathrm{~min}$ at $4^{\circ} \mathrm{C}$. Chromatin was digested with $3 \times 10$ sec 925 sonication at $30 \%$ intensity with a Vibra-Cell probe. The supernatant was collected by 926 centrifugation at $1300 \mathrm{rpm}$ for $30 \mathrm{~min}$ at $4^{\circ} \mathrm{C}$, and then diluted to $200 \mathrm{mM} \mathrm{KCl}$ concentration with no $927 \mathrm{KCL}$ buffer. $30 \mu \mathrm{l}$ of Dynabeads (Invitrogen) were used per co-IP. Beads were washed 2x in $928200 \mathrm{mM} \mathrm{KCI}$ IP Buffer, re-suspended in IP Buffer with 10 $\mu \mathrm{g}$ of the IP antibody, or an IgG-containing 929 serum to match the species of the IP antibody and placed on rotator for $5 \mathrm{~h}$ at $4^{\circ} \mathrm{C}$. Beads were 930 washed $3 x$ in IP buffer and then incubated in $1 \mathrm{mg}$ chromatin lysate on a rotator overnight at $4^{\circ} \mathrm{C}$. 931 The beads were washed, re-suspended in 2X Laemmli Buffer (Bio-Rad), boiled for 10min at $95^{\circ} \mathrm{C}$ 932 and used for WB as above.

934 Immunofluorescence and Microscopy

935 ES cells were cultured on fibronectin or gelatin-coated cover glass in 6-well plates. Cells were 936 fixed in 4\% Paraformaldehyde for $5 \mathrm{~min}$ and incubated in $0.1 \%$ Triton X-PBS for $10 \mathrm{~min}$ before 937 being washed and blocked in 10\% FCS-PBS for 20min. Primary antibodies were diluted in 10\% 938 FCS, $0.1 \%$ Saponin (Sigma) and incubated overnight at $4^{\circ} \mathrm{C}$. The next day, the cells were 
939 incubated with an Alexa fluorophore-conjugated secondary antibody diluted in $10 \%$ FCS, $0.1 \%$

940 Saponin for $1 \mathrm{hr}$ at room temperature, washed and mounted on cover slides with ProLong

941 Diamond Antifade Mountant with DAPI (Invitrogen). Z-stacks imaging of fixed cells was done

942 using a LSM 880 confocal microscope (Zeiss) with a 63X oil objective. Analysis was performed

943 using Imaris 9.6 (Oxford instruments). Live cell imaging was performed using a 3i Spinning Disc

944 confocal microscope (Zeiss). Stag1-mNG-V5-FKBP12 ${ }^{\mathrm{F} 36 \mathrm{~V}}$ cells were seeded in an 8-chambered

945 coverglass (Lab-Tek II) and DMSO or dTAG (500nM) were added for $24 \mathrm{hr}$ before imaging.

946 Directly prior to imaging, cells were incubated with Hoechst 33342 (BD Pharmingen) for 45min,

947 and then replaced with fresh $2 \mathrm{i}$ ES media. Cells were imaged as confocal Z-stacks using DAPI

948 and GFP lasers with a 63X objective and 1.4 Numerical Aperture.

949

950 Antibodies used in this study

\begin{tabular}{|l|l|l|l|}
\hline Protein & Catalogue No. & Company & Figure references \\
\hline Stag1/SA1, N-term epitope & ab4455 & Abcam & $\begin{array}{l}\text { 1B, C, I, S1C, K, 2C, } \\
\text { S2C, E, 3J, S3G, 4C, } \\
\text { F, 5J }\end{array}$ \\
\hline Stag1/SA1, C-term epitope & ab4457 & Abcam & 25, 3I \\
\hline Stag2/SA2 & A300-158A & Bethyl & 1B, S1C \\
\hline Smc3 & ab9263 & Abcam & 1B, 2C \\
\hline Nanog & ab70482 & Abcam & 1E, S1F \\
\hline Tubulin (Tub) & T5168 & Sigma & 1C, 1I, S2E, 4C, S6A \\
\hline Actin & Mab8929 & Novus & S1C \\
\hline H3 & ab1791 & Abcam & 1C \\
\hline v5 & $14-6796-82$ & Invitrogen & 3K \\
\hline HP1a & 2616 & Cell Signalling & 2C, S2B, C \\
\hline Nucleolin (Ncl) & ab22758 & Abcam & 2C, 5J, 6A, S6A \\
\hline H3K9me3 & ab8898 & Abcam & 2F, I, S2E, 5A, S5A \\
\hline H3K4me3 & ab8580 & Abcam & S2E \\
\hline Alexa488-anti-GFP (GFP) & A-21311 & ThermoFisher & 2I, S2A, B, 5A \\
\hline Trim28 & MA1-2023 & ThermoFisher & 5J \\
\hline & & & \\
\hline
\end{tabular}

952 Chromatin accessibility analysis by DNase I treatment.

953 DNase I digestion was performed as in Huo et al (Mol Cell, 2020), with modifications. 200,000

954 cells per condition were resuspended in DNasel digestion buffer (50mM Tris- $\mathrm{HCl} \mathrm{pH} 7.5,5 \mathrm{mM}$ 
$955 \mathrm{MgCl}_{2}, 0.1 \mathrm{mM} \mathrm{CaCl}_{2}, 0.2 \%$ Triton $\mathrm{X}, 5 \mathrm{mM} \mathrm{Na}$ butyrate, protease inhibitor) and incubated for 10

$956 \mathrm{~min}$ at room temp. DNase I (50U/ $\mu \mathrm{l}$, ThermoFisher ES0523) was diluted in 1X DNase buffer and

957 added to cells to have the following Units/ $\mu \mathrm{l}: 1.25,2.5,5,7.5$ and 10. Cells were incubated at 37C

958 for $10 \mathrm{~min}$ in the thermoblock, shaking at 1,000 rpm. To stop the digestion, 10 $\mu$ l 0.5M EDTA and

$95910 \mathrm{ul} 10 \%$ SDS was added and incubated 10-15min at room temperature. $400 \mu$ TE buffer was

960 added, followed by $10 \mu \mathrm{l}$ PureLink RNaseA (ThermoFisher, 20mg/ml, 12091021), and incubated

961 at $37 \mathrm{C}$ for $1 \mathrm{hr}$. Proteinase $\mathrm{K}$ digestion was then performed by adding $100 \mu \mathrm{g}$ of Proteinase $\mathrm{K}$ and

962 incubating at $55 \mathrm{C}$ for $3 \mathrm{hr}$ to overnight. To isolate DNA, $30 \mu \mathrm{l}$ of $5 \mathrm{M} \mathrm{NaCl}$ and $525 \mu$ I Isopropanol

963 was added, DNA precipitated at room temperature for $15 \mathrm{~min}$, pelleted by high speed

964 centrifugation at 4C for $20 \mathrm{~min}$, dried, resuspended in $20 \mu \mathrm{l}$ of TE buffer and loaded on $1 \%$ agarose

965 gel. The gel was stained using SYBR Green.

966

\section{Nascent transcription and translation analysis}

968 For nascent transcription analysis, we used the Click-iTß RNA Alexa Fluor ${ }^{\circledR} 488$ HCS Assay 969 (Invitrogen C10327). ES cells were labelled with $1 \mathrm{mM} \mathrm{EU}$ for $45 \mathrm{~min}$ at $37 \mathrm{C}$ in fresh ES 970 media. Cells were fixed in solution or onto coverslips with $3.7 \%$ paraformaldehyde and 971 permeabilised with $0.5 \%$ Triton-X solution. Cells were incubated with the Click-iT reaction 972 cocktail for 30min. Cells were then either processed further for Immunofluorescence as 973 per methods described above (directly to the blocking step) or analysed by flow cytometry 974 on a BD Fortessa X20. For the Nascent translation analysis, Click-iT ${ }^{\mathrm{TM}}$ HPG Alexa Fluor ${ }^{\text {TM }} 594$

975 Protein Synthesis Assay Kit (Invitrogen C10429) was used. Cells were pre-incubated in 976 Methionine-free media for $30 \mathrm{~min}$ in the $37 \mathrm{C}$ incubator before addition of L-homopropargylglycine 977 (HPG) at $50 \mu \mathrm{M}$. Cells were incubated with HPG for $30 \mathrm{~min}$, then collected, fixed, permeabilized, 978 and stained using Click-It reaction in low retention tubes. HPG incorporation was measured by 979 Flow Cytometry. FACS analysis (in Figures 5,6) was done with FloJo software (version 10.7.1).

981 Next generation Sequencing and Analysis

982 Genomic data generated in this study (RNA-seq, PacBio-seq and UMI4C-seq) was submitted to 983 GEO with the Accession GSE160390.

984

985 RNA sequencing (RNA-seq) library preparation and sequencing

986 ES cells were treated for 24hrs with siRNA pools to Stag1 (SA1) and two sets of control siRNAs, 987 scrambled (SCR) and Luciferase (Luc). There are three replicate sets for SP KD and two for the 
siRNA pools (SATS, 3p, 5p). Total RNA was isolated using NEB Monarch RNA prep kit. $1 \mu \mathrm{g}$ of total RNA was rRNA-depleted using NEBNext rRNA depletion kit (Human/Mouse/Rat). Libraries were prepared from 10-50ng rRNA-depleted total RNA, depending on availability of material, using NEBNext Ultra II directional RNAseq kit according to manufacturer's instructions using 8 cycles of PCR. All ESC FCS libraries were rRNA depleted and only the ESC $2 \mathrm{i}$ libraries were

993 PolyA-enriched before library prep. Two rounds of PolyA+ enrichment were performed. RNA-seq 994 libraries were sequenced on the Illumina HiSeq3000 platform, 75bp paired-end or single-end 995 reads. Reads were quality controlled using FASTQC. RNA-seq data was processed using the 996 RNA-seq Nextflow pipeline (v19.01.0), with the following parameters -aligner hisat2 -genome mm10, with -reverse_stranded specified for paired-end samples. FeatureCounts output was parsed through edgeR (v3.16.5) and DESeq2 (v1.14.1) to generate normalised expression counts. The normalised counts for RNAseq (Figure 1) were calculated in edgeR. Low expressed genes were removed (rowSum cpm <2 across SCR and SA1SP replicates), normalisation factors were calculated using calcNormFactors and dispersions estimated using estimateDisp. The edgeR volcano plot statistics were calculated using the exactTest and topTags functions. To generate the normalised counts for RNAseq experiments required to calculate the log2FC GSEA

1004 ranked lists, the FeatureCounts output for all experiments was combined into a single table and 1005 read into DESeq2. A DESeq2 object was built using the function DESeqDataSetFromMatrix and 1006 estimation of size factors and dispersions were calculated using the DEseq function. Normalised 1007 counts were calculated using the 'counts' function. Low expressed genes (rowSum normalised 1008 count $<10$ across all samples) were removed.

\section{GSEA}

1011 Broad Institute GSEAPreranked (v4.0.3) was used to determine the enrichment of curated 1012 genesets within our RNA-seq data. For each sample a ranked list was generated with genes 1013 ranked in descending order by their log2FC value using normalised expression scores from 1014 DEseq2. Log2FC per gene was calculated between the KD and its respective SCR using the 1015 following calculation: Log2(normalised_counts KD +1) - $\log 2($ normalised_counts SCR +1 ). In the 1016 case of experiments with multiple KD replicates, the average log2 normalised count was used. 1017 Three gene sets were assayed in this study, 'naïve pluripotency', 'primed pluripotency' and '2C 1018 signatures'. The naïve and primed pluripotency gene sets were curated in-house from Fidalgo M 1019 et al. (CSC, 2016) where genes were selected if they had $\geq 2$ fold change. The naïve and primed 1020 gene sets contained 661 and 580 genes respectively. The 2C signatures gene set (147 genes) 
1021 was obtained from Percharde $\mathrm{M}$ et al. (Cell, 2018). Gene sets were classed as having significant 1022 enrichment if the $p$-value was $\leq 0.05$ and the normalised enrichment score (NES) exceeded $+/-1$.

\section{VAST-TOOLS}

1025 VAST-TOOLS was used to generate Percent Spliced In (PSI) scores, a statistic which represents

1026 how often a particular exon is spliced into a transcript using the ratio between reads which include 1027 and exclude said exon. Paired-end RNA-seq datasets were submitted to VAST-TOOLS (v2.1.3) 1028 using the Mmu genome (Tapial J et al, Gen Res 2017). Briefly, reads are split into 50nt words 1029 with a $25 \mathrm{nt}$ sliding window. The 50nt words are aligned to a reference genome using Bowtie to 1030 obtain unmapped reads. These unmapped reads are then aligned to a set of predefined exon1031 exon junction (EJJ) libraries allowing for the quantification of alternative exon events. The output 1032 was further interrogated using a script which searches all hypothetical EEJ combinations between 1033 potential donors and acceptors within Stag1. PSI scores could be obtained providing there was 1034 at least a single read within our RNAseq data that supported one of these potential events. Some 1035 datasets were combined to have enough reads for the analysis. See Table S1 for PSI values and names of RNA-seq libraries used for analysis in Figure 3E and S4B.

\section{Quantifying sectioned Stag1}

1039 Stag1 was split into 5 sections; SATS, e1-e8, e12-e19, e20-e25, e26-e34. Using Kallisto 1040 (v0.46.1), raw RNAseq reads were used to quantify each section of Stag1. Kallisto was run in 1041 quant mode, using the -rf-stranded parameter, outputting a TPM per Stag1 section. A line plot was generated showing TPM in relative to UT.

\section{PacBio library, sequencing and analysis}

1045 ES cells were cultured in naïve 2i conditions and PolyA-enriched mRNAs were hybridized to a 1046 custom Biotinylated oligonucleoltide probe set. Post-capture, mRNAs were amplified using the 1047 Clontech SMARTer PCR cDNA Synthesis Kit with 9 cycles and used in the SMRTbell library prep 1048 according to manufacturers instructions. The library was sequenced on the SMRTseq 2000 1049 platform. PacBio reads were processed through the SMRTLINK v8.0.0 IsoSeq3 pipeline. 403,995 1050 Circular consensus sequences (CCS) were generated using default parameters (--minPasses = 1051 1, --min-rq = 0.8, CCS Polish = No). Further refining through lima (removal of adapters and correct 1052 orientation of sequences), poly-A trimming and concatemer removal resulted in 265,106 full length 
1053 non-chimeric (FLNC) reads. FLNC reads were aligned to the mm10 genome using Minimap2 with

1054 the following parameters (-ax splice, -uf, -k14).

\section{ChIP-seq Analysis}

1057 Previously published Stag1 Chromatin Immunoprecipitation-sequencing (ChIP-seq) datasets

1058 from ES $2 \mathrm{i}$ cells (GSE126659, only Replicate 1 and 2 libraries) were trimmed using trim_galore

1059 and aligned to mm10 using bowtie2. Peak detection was performed with MACS2 using uniquely

1060 reads $(M A P Q \geq 2)$. Peaks were overlapped with genomic features in a hierarchical manner

1061 (promoters > exons > repeats > introns > intergenic), and overlap frequency was compared with

1062 a randomly shuffled version of the peaks. To identify repeat families enriched for STAG1 peaks,

1063 a previously described pipeline was used (Deniz O et al. Nat Comm, 2020) that compares family-

1064 levels overlap frequency with that observed in 1,000 permutations of random peak shuffling.

1065 Coverage profiles across specific TE families were generated using HOMER and including multi-

1066 mapping reads (MAPQ<2).

1067

1068 UMI-4C library preparation.

$10691 \times 10^{7}$ cells were fixed at RT for $10 \mathrm{~min}$ in $1 \%$ formaldehyde and fixation was quenched with $0.125 \mathrm{M}$

1070 Glycine for $5 \mathrm{~min}$. Cells were then lysed on ice in $10 \mathrm{ml}$ Lysis Buffer $(10 \mathrm{mM} \mathrm{NaCl}, 10 \mathrm{mM}$ Tris- $\mathrm{HCl}$

$1071 \mathrm{pH} 8.0,0.25 \%$ NP40, protease inhibitor) for 30min, followed by 10 strokes of douncing using a

1072 tight pestle. Nuclei were pelleted, 8min 700 rcf, washed in $1 \mathrm{ml} 1.2 X$ Dpnll buffer in Protein LoBind

1073 tubes (Eppendorf) and resuspended in $500 \mu \mathrm{l}$ 1.2X Dpnll buffer. 15ul of 10\% SDS was added

1074 and incubated for $1 \mathrm{hr}$ at $37^{\circ} \mathrm{C}$ shaking at $650 \mathrm{rcf}$. $50 \mathrm{ul}$ of $\mathbf{2 0 \%}$ TritonX was added to quench the

1075 SDS and incubated for $15 \mathrm{~min}$ at $37^{\circ} \mathrm{C}$ with shaking. $750 \mathrm{U}$ of Dpnll was added and incubated

1076 overnight at $37^{\circ} \mathrm{C}$ with interval shaking. The next morning, nuclei were pelleted at $4^{\circ} \mathrm{C}$ by

$1077650 \mathrm{rcf}$ for $5 \mathrm{~min}$ and resuspended in 500 $\mu$ 1X Dpnll buffer. 500U Dpnll was added and incubated

1078 for an additional four hours. The nuclei were washed twice in $100 \mu \mathrm{l}$ of 1X T4 Ligase Buffer and 1079 resuspended in $200 \mu \mathrm{l}$ Ligase Buffer. 6ul of T4 DNA Ligase was added and incubated for 3hr

1080 at $16^{\circ} \mathrm{C}$. Nuclei were then pelleted, resuspended in $200 \mu \mathrm{l}$ x fresh Ligase Buffer, $6 \mu$ of T4 DNA

1081 Ligase added, and incubated overnight at $16^{\circ} \mathrm{C}$. Samples were treated with $20 \mu$ of ProtK (NEB

1082 Molecular Biology Grade), incubated for $3 \mathrm{hrs}$ at $55^{\circ} \mathrm{C}$ and $5 \mathrm{hrs}$ at $65^{\circ} \mathrm{C}$ to reverse crosslinks.

1083 Samples were treated with RNase A (PureLink, Invitrogen) for $1 \mathrm{hr}$ at $37^{\circ} \mathrm{C}$ and DNA was

1084 extracted and precipitated overnight. For library preparation, $3 \times 5 \mu \mathrm{g}$ of ligated DNA was sonicated

1085 using Covaris (10\% duty cycle, intensity 5, cycle burst 200, 70sec). Samples were end-repaired 
1086 using DNA Polll Klenow Large Fragment (NEB), A-tailed using Klenow (exo-) (NEB), and Illumina

1087 indexed adapters ligated using Quick DNA Ligase (NEB). Reactions were denatured at $95^{\circ} \mathrm{C}$ for $10883 \mathrm{~min}$, placed on ice, and purified using 1.2X SizeSelect AmpPure beads to recover ssDNA. 1089 Libraries were amplified using GoTaq (Promega), with 20 cycles for PCR1 and 15 cycles for 1090 nested PCR2 on 50\% material from $1^{\text {st }}$ PCR. For custom UMI bait sequences, see Table S3.

\section{Hi-C and UMI-4C-seq analysis}

1093 Hi-C libraries were analysed as previously described (Barrington 2019). UMI-4C tracks were 1094 processed using the 'umi4cPackage' pipeline (v0.0.0.9000) (Schwartzman, O et al. Nat Meth 1095 2017). Briefly, raw reads are parsed through the UMI-4C pipeline, those reads containing the bait 1096 and padding sequence are retained and de-multiplexed. Reads lacking the padding sequence are 1097 considered non-specific and are removed from further analysis. Retained reads are split based 1098 on a match to the restriction enzyme sequence to create a segmented fastq file. The first 10 bases 1099 of read 2 are extracted and attached to the segments derived from each read pair. Mapping to $1100 \mathrm{~mm} 10$ is done with Bowtie2. Read pairs that have reverse complement segments are mapped to 1101 a restriction fragment ID, with the fragment ID, strand and distance from each end represented 1102 within a fragment-chain table. UMI filtering is used to determine the number of molecules 1103 supporting each ligation event. The resulting UMI-4C tracks are then imported into $\mathrm{R}$, and data 1104 from multiple bait replicates can be merged by summing the molecule counts per ligated fragment, 1105 at which point contact intensity profiles and domainograms around the viewpoint can be 1106 generated (see Figure 3). The contact intensity profile represents the mean number of ligations 1107 within a genomic window, with the resolution of the contact intensity profile being determined by 1108 the window size (set to 15 here). The domainogram reports the mean contact per fend at a series 1109 of window sizes, a stacked representation of contact intensity values in increasing window sizes 1110 from 10 to 300 fragment ends, their colour can be used to identify peak locations. ES and NSC 1111 contact profiles were compared after normalisation to correct for bias (see Schwartzman et al for 1112 further details). For the compared profiles, the total molecule count for restriction fragment ends

1113 for each are calculated at three ranges around the viewpoint. One profile is selected as a 1114 reference and the second is scaled to the first using the ratio in total molecule counts between 1115 the two profiles as the scaling factor. Below the contact profile is the profile resolution indicator, 1116 which shows the number of fends required to include at least $15 \mathrm{UMI}$ molecules. The darker the 1117 colour, the larger the window size required. The domainogram at the bottom represents the log2 
bioRxiv preprint doi: https://doi.org/10.1101/2021.02.14.429938; this version posted February 16, 2021. The copyright holder for this preprint

(which was not certified by peer review) is the author/funder, who has granted bioRxiv a license to display the preprint in perpetuity. It is made available under aCC-BY 4.0 International license.

1118 ratio between the domainogram values of the compared profiles and highlights locations where 1119 ES has more contacts than NSC or vice versa.

1120 


\section{Supplementary titles and legends.}

\section{Figure S1. Stag1 is required for pluripotency, Related to Figure 1.}

1123 (A) Cartoon of the cohesin complex including the core trimer subunits of Smc1a, Smc3 1124 and Rad21 complexed with either Stag1 or Stag2.

1125 (B) Relative expression of Stag1 and Stag2 mRNA by qRT-PCR in 2i- or FCS-grown ES 1126 cells, EpiLCs and MEFs. Data is represented as mean \pm SEM of two independent 1127 experiments and relative to Actin control expression.

1128 (C) WCL from naïve (2i) ES and EpiLCs, sorted for cells in the G1 phase and analyzed 1129 by WB for levels of SA1 and SA2. Actin serves as a loading control.

1130 (D) Relative expression of Stag1 mRNA by qRT-PCR in FCS- (left panel, $\mathrm{n}=20$ ) or 2i1131 grown (right panel, $\mathrm{n}=19$ ) ES cells upon treatment with si scr or si SA1. Whiskers and 1132 boxes indicate all and $50 \%$ of values respectively. Central line represents the median.

1133 (E) Cell cycle analysis of Hoechst-stained 2i ES cells after treatment with siScr or siSA1 1134 siRNAs for 24hrs. Shown are the percentages of cells in G1 or G2 phases. These are the 1135 same cells that were used for the RNA-sequencing experiments shown in Figure 1F.

1136 (F) MFI of Stag1 protein assessed by IF in 2i ES cells treated with si scr and si SA1. Cells 1137 were stained for SA1 and counterstained with DAPI. Data is from the second biological 1138 replicate (replicate 1 is in Fig $1 \mathrm{E}$ ), $n>100$ cells/condition ${ }^{* * *} p<0.0005$.

1139 (G) Enrichment score (ES) plots from GSEA using Naïve or Primed gene sets as in Figure $11401 \mathrm{G}$ and RNA-seq data from the other two siSA1 treated ES cell samples.

1141 (H) AP+ colonies in ES cells (purple), as a percentage of all colonies (pink and purple) 1142 treated with siscr and si SA1. Data are from three independent biological replicates and 1143 merged. See Fig $1 \mathrm{H}$ for the individual experiments.

1144 (I-K) CRISPR/Cas9 targeting of the C-terminus of endogenous Stag1. (I) Schematic of 1145 the targeted locus and location of primers used for genotyping. (J) Shown are four ES cell 1146 clones representing integration into both alleles, one allele and a wildtype clone. (K) IF 1147 using the v5 tag in a homozygote clonal line treated with dTAG for $16 \mathrm{hrs}$ shows complete 1148 loss of the NeonGreen signal. 
1151 Figure S2. Stag1 associates with heterochromatin, Related to Figure 2.

1152 (A, B) Confocal IF images in dox-inducible full-length SA1-GFP ES cells (SA1-FL-GFP) 1153 stained with (A) GFP and (B) HP1a. Nuclei were counterstained with DAPI. NB, 1154 colocalization of SA1-GFP with DAPI-dense foci and HP1a.

1155 (C) Replicate experiment for co-Immunoprecipitation of endogenous SA1 with Smc3, 1156 HP1a and Nucleolin in ES cells.

1157 (D) Enrichment of Stag1 ChIP at additional LTR and DNA transposon elements.

1158 (E) WCL from ES treated with the siRNA panel and analyzed by WB for levels of SA1, $1159 \mathrm{H} 3 \mathrm{~K} 9 \mathrm{me} 3$ and K3K4me3. Tubulin serves as a loading control.

1160 (F) Global chromatin accessibility as detected by DNase I digestion of genomic DNA in 1161 siScr or siSA1 ES cells. NB, In two of six biological replicates, we observed increased 1162 compaction upon SA1 loss, as is shown here.

1164 Figure S3. Transcription-Regulatory Control of Stag1 in ESC, Related to Figure 3.

1165 (A) Aligned Stag1 transcript variants identified from 5'RACE in Figure 3A, B. Arrows refer 1166 to the bands on the RACE gels which were cloned and sequenced. NB, the diversity of 1167 skipping events that all result in a functional loss of the 5' end of Stag1.

1168 (B) Over-exposure of the 5'RACE gel shown in Figure 3B to better show the small RACE 1169 products.

1170 (C) Close-up of the 5' RACE sequence that identified a new TSS at exon 7 spliced directly 1171 to a sequence in trans carrying regulatory elements.

1172 (D) Close-up of the 3' RACE sequence that identified a new alternative TTS in intron 25 1173 (sequence shown in dark blue).

1174 (E) Initial PCR screen in ES 2i and MEFs using various combinations of forward (5') 1175 primers (SATS, canonical TSS, Alt exon 1 TSS) and reverse (3') primers (canonical TTS, 1176 Alt intron 25 TTS). NB. SATS is only expressed in ES cells; canonical, full-length Stag1 1177 is more expressed in ES compared to MEFs; and the alternative intron 25 TTS is most 1178 often expressed with a canonical TSS. 
1179 (F) Top, Strategy for mRNA capture of cohesin genes for Pac-Bio long read RNA1180 sequencing. Bottom, full-length transcripts sequenced on the PacBio platform includes 1181 many isoforms already discovered using RACE and PCR cloning methods.

1182 (G) Chromatin Immunoprecipitation of SA1 in ES and EpiLCs.

1184 Figure S4. Fluctuations in Stag1 isoforms skews cell fates, Related to Figure 4.

1185 (A) Relative expression of Stag1 mRNA by qRT-PCR in FCS- (leftmost and rightmost 1186 panels, $n=7$ ) or 2i-grown (middle panel, $n=6$ ) ES cells upon si scr or the si SA1 panel. 1187 Whiskers and boxes as before. NB, all siRNAs knockdown Stag1 levels to a similar extent 1188 with the exception of esiRNA SATS which reduced Stag1 by $\sim 40-50 \%$.

1189 (B) Percent Spliced In (PSI) calculations based on VAST-Tools analysis of RNA-seq from 1190 ES cells treated with the siRNA panel. Data are shown relative to untreated ES cells.

1191 (C) Relative expression of Nanog mRNA by qRT-PCR in FCS-grown ES cells upon si scr 1192 or the si SA1 panel $(n=13)$. Whiskers and boxes as before. NB, the modest, but different 1193 influence of the $5 p$ and the $3 p$ KDs on Nanog levels.

1194 (D) AP+ colonies in ES cells (purple), as a percentage of all colonies (pink and purple) 1195 treated with the siRNA panel. Data are from two independent biological replicates and 1196 merged. See Fig 4H for the individual experiments.

1198 Figure S5. Stag1 N-terminus represses heterochromatin and reprograms cells, 1199 Related to Figure 5.

1200 (A) Confocal IF images of GFP and H3K9me3 in ES cells treated with siRNA panel. Nuclei 1201 were counterstained with DAPI.

1202 (B) Imaris quantification of the volume of H3K9me3 foci per cell from (A). Box plots and 1203 statistical analysis were done as before. Data are from two biological replicates, $1204 \mathrm{n}>50 /$ condition. ${ }^{* * * *} \mathrm{p}<0.0005$.

1205 (C) Global chromatin accessibility as detected by DNase I digestion of genomic DNA in 1206 siScr or siSA1 3p or 5p ES cells. NB. There was no effect on accessibility in the 3p KD 1207 but a consistent decompaction observed in the 5p KD. 
1208 (D, E) Relative expression of (C) MERVL and (D) genes associated with the 2C-L state 1209 by qRT-PCR in 2i-grown ES cells after 72hr of treatment with si scr or the si SA1 panel. 1210 Data are represented as mean $+/$ - SEM from $n=3$ biological replicates. NB, the effect of 1211 the $5 p \mathrm{KD}$ on the expression of these hallmark $2 \mathrm{C}-\mathrm{L}$ genes/repeats is much more 1212 significant than in the FCS-grown ES cells shown in Figure 5C, D.

1213 (F) Enrichment score (ES) plots from GSEA using 2C gene sets as in Figure 5E and 1214 RNA-seq data from the different siRNA treated ES cell samples.

1216 Figure S6. Stag1 deregulates nascent rRNA expression, Related to Figure 6.

1217 (A) WCL from ES cells treated with the siRNA panel and analyzed by WB for global levels 1218 of Nucleolin. Tubulin serves as a loading control.

1219 (B) Top, cartoon of the consensus Mus musculus ribosomal DNA (rDNA) (GenBank: 1220 BK000964.3), showing the ribosomal genes and the intergenic spacer (IGS) region which 1221 contains several SINE elements (Red, B2_Mm2; Green, B3). Bottom, Stag1 ChIP 1222 replicates aligned to this region. NB, possible Stag1 binding to the B3 elements in the 1223 IGS. 


\section{REFERENCES}

1226 Ahmed, K., Dehghani, H., Rugg-Gunn, P., Fussner, E., Rossant, J., and Bazett-Jones, D.P. (2010). Global chromatin architecture reflects pluripotency and lineage commitment in the early mouse embryo. PLoS ONE 5, e10531.

1229 Allshire, R.C., and Madhani, H.D. (2018). Ten principles of heterochromatin formation and 1230 function. Nat. Rev. Mol. Cell Biol. 19, 229-244.

1231 Banani, S.F., Lee, H.O., Hyman, A.A., and Rosen, M.K. (2017). Biomolecular condensates: 1232 organizers of cellular biochemistry. Nat. Rev. Mol. Cell Biol. 18, 285-298. occupancy underlie asymmetric TAD architecture and cell type specific genome topology.

1235 Nature Communications.

1236 Bickmore, W.A., and van Steensel, B. (2013). Genome architecture: domain organization of interphase chromosomes. Cell 152, 1270-1284.

1238 Bisht, K.K., Daniloski, Z., and Smith, S. (2013). SA1 binds directly to DNA through its unique 1239 AT-hook to promote sister chromatid cohesion at telomeres. J. Cell. Sci. 126, 3493-3503.

1240 Bonev, B., and Cavalli, G. (2016). Organization and function of the 3D genome. Nat. Rev.

1241 Genet. 17, 661-678.

1242 Bonev, B., Cohen, N.M., Szabo, Q., Fritsch, L., Papadopoulos, G.L., Lubling, Y., Xu, X., Lv, X., Hugnot, J.-P., Tanay, A., et al. (2017). Multiscale 3D Genome Rewiring during Mouse Neural

Borsos, M., and Torres-Padilla, M.-E. (2016). Building up the nucleus: nuclear organization in

1248 Buszczak, M., Signer, R.A.J., and Morrison, S.J. (2014). Cellular Differences in Protein

1250 Canudas, S., and Smith, S. (2009). Differential regulation of telomere and centromere cohesion by the Scc3 homologues SA1 and SA2, respectively, in human cells. J Cell Biol 187, 165-173.

Cardozo Gizzi, A.M., Cattoni, D.I., Fiche, J.-B., Espinola, S.M., Gurgo, J., Messina, O., 
3D genome architecture. Curr. Opin. Genet. Dev. 61, 9-16.

1261 Cuadrado, A., Giménez-Llorente, D., Kojic, A., Rodriguez-Corsino, M., Cuartero, Y., MartínContributions of Cohesin-SA1 and Cohesin-SA2 to TADs and Polycomb Domains in Embryonic Stem Cells. Cell Rep 27, 3500-3510.e3504.

1265 Cuartero, S., Weiss, F.D., Dharmalingam, G., Guo, Y., Ing-Simmons, E., Masella, S., RoblesRebollo, I., Xiao, X., Wang, Y.-F., Barozzi, I., et al. (2018). Control of inducible gene expression links cohesin to hematopoietic progenitor self-renewal and differentiation. Nat Immunol 19, 932941.

Deniz, Ö., Ahmed, M., Todd, C.D., Rio-Machin, A., Dawson, M.A., and Branco, M.R. (2020). Endogenous retroviruses are a source of enhancers with oncogenic potential in acute myeloid leukaemia. Nature Communications 11, 3506-3514.

1274 Dixon, J.R., Selvaraj, S., Yue, F., Kim, A., Li, Y., Shen, Y., Hu, M., Liu, J.S., and Ren, B. (2012). 1275 Topological domains in mammalian genomes identified by analysis of chromatin interactions.

1276 Nature 485, 376-380.

Eckersley-Maslin, M.A., Svensson, V., Krueger, C., Stubbs, T.M., Giehr, P., Krueger, F., Miragaia, R.J., Kyriakopoulos, C., Berrens, R.V., Milagre, I., et al. (2016). MERVL/Zscan4 Network Activation Results in Transient Genome-wide DNA Demethylation of mESCs. Cell Rep 17, 179-192.

1281 Feng, G., Tong, M., Xia, B., Luo, G.Z., Wang, M., Xie, D., Wan, H., Zhang, Y., Zhou, Q., and Wang, X.J. (2016). Ubiquitously expressed genes participate in cell-specific functions via alternative promoter usage. EMBO Rep. 17, 1304-1313.

1284 Finn, E.H., Pegoraro, G., Brandão, H.B., Valton, A.-L., Oomen, M.E., Dekker, J., Mirny, L., and 1285 Misteli, T. (2019). Extensive Heterogeneity and Intrinsic Variation in Spatial Genome 1286 Organization. Cell 176, 1502-1515.e1510.

1287 Fiszbein, A., and Kornblihtt, A.R. (2017). Alternative splicing switches: Important players in cell 1288 differentiation. Bioessays 39, 1600157.

1289 Gabut, M., Samavarchi-Tehrani, P., Wang, X., Slobodeniuc, V., O'Hanlon, D., Sung, H.-K., Alvarez, M., Talukder, S., Pan, Q., Mazzoni, E.O., et al. (2011). An alternative splicing switch regulates embryonic stem cell pluripotency and reprogramming. Cell 147, 132-146.

1292 Guelen, L., Pagie, L., Brasset, E., Meuleman, W., Faza, M.B., Talhout, W., Eussen, B.H., de Klein, A., Wessels, L., de Laat, W., et al. (2008). Domain organization of human chromosomes revealed by mapping of nuclear lamina interactions. Nature 453, 948-951.

1295 Haarhuis, J.H.I., van der Weide, R.H., Blomen, V.A., Yáñez-Cuna, J.O., Amendola, M., van 1296 Ruiten, M.S., Krijger, P.H.L., Teunissen, H., Medema, R.H., van Steensel, B., et al. (2017). The 1297 Cohesin Release Factor WAPL Restricts Chromatin Loop Extension. Cell 169, 693-707.e14. 
1298

1299

1300

1301

1302

1303

1304

1305

1306

1307

1308

1309

1310

1311

1312

1313

1314

1315

1316

1317

1318

1319

1320

1321

1322

1323

1324

1325

1326

1327

1328

1329

1330

1331

1332

1333

1334

1335

Hadjur, S., Williams, L.M., Ryan, N.K., Cobb, B.S., Sexton, T., Fraser, P., Fisher, A.G., and Merkenschlager, M. (2009). Cohesins form chromosomal cis-interactions at the developmentally regulated IFNG locus. Nature 460, 410-413.

Hara, K., Zheng, G., Qu, Q., Liu, H., Ouyang, Z., Chen, Z., Tomchick, D.R., and Yu, H. (2014). Structure of cohesin subcomplex pinpoints direct shugoshin-Wapl antagonism in centromeric cohesion. Nature Publishing Group 21, 864-870.

Hendrickson, P.G., Doráis, J.A., Grow, E.J., Whiddon, J.L., Lim, J.-W., Wike, C.L., Weaver, B.D., Pflueger, C., Emery, B.R., Wilcox, A.L., et al. (2017). Conserved roles of mouse DUX and human DUX4 in activating cleavage-stage genes and MERVL/HERVL retrotransposons. Nat. Genet. 49, 925-934.

Horsfield, J.A., Anagnostou, S.H., Hu, J.K.-H., Cho, K.H.Y., Geisler, R., Lieschke, G., Crosier, K.E., and Crosier, P.S. (2007). Cohesin-dependent regulation of Runx genes. Development 134, 2639-2649.

Hung, S.S.C., Wong, R.C.B., Sharov, A.A., Nakatake, Y., Yu, H., and Ko, M.S.H. (2013).

Repression of global protein synthesis by Eif1a-like genes that are expressed specifically in the two-cell embryos and the transient Zscan4-positive state of embryonic stem cells. DNA Res 20, 391-402.

Ishiuchi, T., Enriquez-Gasca, R., Mizutani, E., Bošković, A., Ziegler-Birling, C., RodriguezTerrones, D., Wakayama, T., Vaquerizas, J.M., and Torres-Padilla, M.-E. (2015). Early embryonic-like cells are induced by downregulating replication-dependent chromatin assembly. Nature Publishing Group 22, 662-671.

Jachowicz, J.W., Bing, X., Pontabry, J., Bošković, A., Rando, O.J., and Torres-Padilla, M.-E. (2017). LINE-1 activation after fertilization regulates global chromatin accessibility in the early mouse embryo. Nat. Genet. 49, 1502-1510.

Kagey, M.H., Newman, J.J., Bilodeau, S., Zhan, Y., Orlando, D.A., van Berkum, N.L., Ebmeier, C.C., Goossens, J., Rahl, P.B., Levine, S.S., et al. (2010). Mediator and cohesin connect gene expression and chromatin architecture. Nature 467, 430-435.

Kline, A.D., Moss, J.F., Selicorni, A., Bisgaard, A.-M., Deardorff, M.A., Gillett, P.M., Ishman, S.L., Kerr, L.M., Levin, A.V., Mulder, P.A., et al. (2018). Diagnosis and management of Cornelia de Lange syndrome: first international consensus statement. Nat. Rev. Genet. 19, 649-666.

Kojic, A., Cuadrado, A., De Koninck, M., Giménez-Llorente, D., Rodriguez-Corsino, M., GomezLopez, G., Le Dily, F., Marti-Renom, M.A., and Losada, A. (2018). Distinct roles of cohesin-SA1 and cohesin-SA2 in 3D chromosome organization. Nature Publishing Group 25, 496-504.

Kresoja-Rakic, J., and Santoro, R. (2019). Nucleolus and rRNA Gene Chromatin in Early Embryo Development. Trends Genet. 35, 868-879.

Larson, A.G., Elnatan, D., Keenen, M.M., Trnka, M.J., Johnston, J.B., Burlingame, A.L., Agard, D.A., Redding, S., and Narlikar, G.J. (2017). Liquid droplet formation by HP1a suggests a role for phase separation in heterochromatin. Nature 547, 236-240. 
Lehalle, D., Mosca-Boidron, A.-L., Begtrup, A., Boute-Benejean, O., Charles, P., Cho, M.T., Clarkson, A., Devinsky, O., Duffourd, Y., Duplomb-Jego, L., et al. (2017). STAG1 mutations cause a novel cohesinopathy characterised by unspecific syndromic intellectual disability. J Med Genet 54, 479-488.

1340 Leiserson, M.D.M., Vandin, F., Wu, H.-T., Dobson, J.R., Eldridge, J.V., Thomas, J.L., Papoutsaki, A., Kim, Y., Niu, B., McLellan, M., et al. (2015). Pan-cancer network analysis identifies combinations of rare somatic mutations across pathways and protein complexes. Nat.

1343 Genet. 47, 106-114.

Li, Y., Haarhuis, J.H.I., Sedeño Cacciatore, Á., Oldenkamp, R., van Ruiten, M.S., Willems, L., Teunissen, H., Muir, K.W., de Wit, E., Rowland, B.D., et al. (2020). The structural basis for cohesin-CTCF-anchored loops. Nature 578, 472-476.

1347 Macfarlan, T.S., Gifford, W.D., Driscoll, S., Lettieri, K., Rowe, H.M., Bonanomi, D., Firth, A., 1348 Singer, O., Trono, D., and Pfaff, S.L. (2012). Embryonic stem cell potency fluctuates with 1349 endogenous retrovirus activity. Nature 487, 57-63.

1350 Martin, C., Beaujean, N., Brochard, V., Audouard, C., Zink, D., and Debey, P. (2006). Genome restructuring in mouse embryos during reprogramming and early development. Dev. Biol. 292, 1352 317-332.

1353 Mateo, L.J., Murphy, S.E., Hafner, A., Cinquini, I.S., Walker, C.A., and Boettiger, A.N. (2019). 1354 Visualizing DNA folding and RNA in embryos at single-cell resolution. Nature 568, 1-24. Hyperdynamic plasticity of chromatin proteins in pluripotent embryonic stem cells. Dev. Cell 10, 105-116.

1358 Mishiro, T., and Tsutsumi, S. (2009). Architectural roles of multiple chromatin insulators at the human apolipoprotein gene cluster. Embo J. 28, 1234-1245.

1360 Misulovin, Z., Schwartz, Y.B., Li, X.-Y., Kahn, T.G., Gause, M., MacArthur, S., Fay, J.C., Eisen, 1361 M.B., Pirrotta, V., Biggin, M.D., et al. (2007). Association of cohesin and Nipped-B with 1362 transcriptionally active regions of the Drosophila melanogaster genome. Chromosoma 117, 891363102.

Mootha, V.K., Lindgren, C.M., Eriksson, K.-F., Subramanian, A., Sihag, S., Lehar, J., 1365 Puigserver, P., Carlsson, E., Ridderstråle, M., Laurila, E., et al. (2003). PGC-1alpha-responsive 1366 genes involved in oxidative phosphorylation are coordinately downregulated in human diabetes. Nat. Genet. 34, 267-273.

1368 Nabet, B., Roberts, J.M., Buckley, D.L., Paulk, J., Dastjerdi, S., Yang, A., Leggett, A.L., Erb, M.A., Lawlor, M.A., Souza, A., et al. (2018). The dTAG system for immediate and targetspecific protein degradation. Nature Chemical Biology 14, 1-16.

1371 Nagano, T., Lubling, Y., Várnai, C., Dudley, C., Leung, W., Baran, Y., Mendelson Cohen, N., 1372 Wingett, S., Fraser, P., and Tanay, A. (2017). Cell-cycle dynamics of chromosomal organization 1373 at single-cell resolution. Nature 547, 61-67. 
Németh, A., Conesa, A., Santoyo-Lopez, J., Medina, I., Montaner, D., Péterfia, B., Solovei, I., Cremer, T., Dopazo, J., and Längst, G. (2010). Initial genomics of the human nucleolus. PLoS Genet. 6, e1000889.

1377 Novo, C.L., Tang, C., Ahmed, K., Djuric, U., Fussner, E., Mullin, N.P., Morgan, N.P., Hayre, J., Sienerth, A.R., Elderkin, S., et al. (2016). The pluripotency factor Nanog regulates pericentromeric heterochromatin organization in mouse embryonic stem cells. Genes Dev. 30, $1101-1115$.

Nozaki, T., Imai, R., Tanbo, M., Nagashima, R., Tamura, S., Tani, T., Joti, Y., Tomita, M., Hibino, K., Kanemaki, M.T., et al. (2017). Dynamic Organization of Chromatin Domains Revealed by Super-Resolution Live-Cell Imaging. Molecular Cell 67, 282-293.e287.

1384 Obradovic, Z., Peng, K., Vucetic, S., Radivojac, P., Brown, C.J., and Dunker, A.K. (2003). Predicting intrinsic disorder from amino acid sequence. Proteins 53 Suppl 6, 566-572.

1386 Orgil, O., Matityahu, A., Eng, T., Guacci, V., Koshland, D., and Onn, I. (2015). A conserved domain in the scc3 subunit of cohesin mediates the interaction with both mcd1 and the cohesin loader complex. PLoS Genet. 11, e1005036.

1389 Padeken, J., and Heun, P. (2014). Nucleolus and nuclear periphery: velcro for heterochromatin. 1390 Curr. Opin. Cell Biol. 28, 54-60.

1391 Parelho, V., Hadjur, S., Spivakov, M., Leleu, M., Sauer, S., Gregson, H.C., Jarmuz, A., CTCF on mammalian chromosome arms. Cell 132, 422-433.

1394 Percharde, M., Lin, C.-J., Yin, Y., Guan, J., Peixoto, G.A., Bulut-Karslioglu, A., Biechele, S., Huang, B., Shen, X., and Ramalho-Santos, M. (2018). A LINE1-Nucleolin Partnership Regulates Early Development and ESC Identity. Cell 174, 391-405.e19.

1397 Phillips-Cremins, J.E., Sauria, M.E.G., Sanyal, A., Gerasimova, T.I., Lajoie, B.R., Bell, J.S.K., Ong, C.-T., Hookway, T.A., Guo, C., Sun, Y., et al. (2013). Architectural protein subclasses shape 3D organization of genomes during lineage commitment. Cell 153, 1281-1295.

1400 Quinodoz, S.A., Ollikainen, N., Tabak, B., Palla, A., Schmidt, J.M., Detmar, E., Lai, M.M., Shishkin, A.A., Bhat, P., Takei, Y., et al. (2018). Higher-Order Inter-chromosomal Hubs Shape 1402 3D Genome Organization in the Nucleus. Cell 174, 744-757.e24.

1403 Rao, S.S.P., Huang, S.-C., Hilaire, B.G.S., Engreitz, J.M., Perez, E.M., Kieffer-Kwon, K.-R., 1404 Sanborn, A.L., Johnstone, S.E., Bascom, G.D., Bochkov, I.D., et al. (2017). Cohesin Loss 1405 Eliminates All Loop Domains. Cell 171, 305-309.e324.

1406 Rao, S.S.P., Huntley, M.H., Durand, N.C., Stamenova, E.K., Bochkov, I.D., Robinson, J.T., Sanborn, A.L., Machol, I., Omer, A.D., Lander, E.S., et al. (2014). A 3D map of the human genome at kilobase resolution reveals principles of chromatin looping. Cell 159, 1665-1680.

1409 Remeseiro, S., Cuadrado, A., Carretero, M., Martínez, P., Drosopoulos, W.C., Cañamero, M., 1410 Schildkraut, C.L., Blasco, M.A., and Losada, A. (2012a). Cohesin-SA1 deficiency drives 1411 aneuploidy and tumourigenesis in mice due to impaired replication of telomeres. Embo J. 31, 
1413 Remeseiro, S., Cuadrado, A., López, G.G., Pisano, D.G., and Losada, A. (2012b). A unique role of cohesin-SA1 in gene regulation and development. Embo J. 31, 2090-2102.

1415 Ricci, M.A., Manzo, C., García-Parajo, M.F., Lakadamyali, M., and Cosma, M.P. (2015). Chromatin fibers are formed by heterogeneous groups of nucleosomes in vivo. Cell 160, 114514171158.

1418 Rodriguez, J., Ren, G., Day, C.R., Zhao, K., Chow, C.C., and Larson, D.R. (2019). Intrinsic Dynamics of a Human Gene Reveal the Basis of Expression Heterogeneity. Cell 176, 213$1420 \quad$ 226.e218.

1421 Romero-Pérez, L., Surdez, D., Brunet, E., Delattre, O., and Grünewald, T.G.P. (2019). STAG 1422 Mutations in Cancer. Trends Cancer 5, 506-520.

1423 Sabari, B.R., Dall'Agnese, A., Boija, A., Klein, I.A., Coffey, E.L., Shrinivas, K., Abraham, B.J., Hannett, N.M., Zamudio, A.V., Manteiga, J.C., et al. (2018). Coactivator condensation at superenhancers links phase separation and gene control. Science 361, eaar3958-13.

1426 Salomonis, N., Schlieve, C.R., Pereira, L., Wahlquist, C., Colas, A., Zambon, A.C., Vranizan, K., Spindler, M.J., Pico, A.R., Cline, M.S., et al. (2010). Alternative splicing regulates mouse embryonic stem cell pluripotency and differentiation. Proc. Natl. Acad. Sci. U.S.a. 107, 1051410519.

1430 Schlesinger, S., and Meshorer, E. (2019). Open Chromatin, Epigenetic Plasticity, and Nuclear Organization in Pluripotency. Dev. Cell 48, 135-150.

1432 Schwalie, P.C., Ward, M.C., Cain, C.E., Faure, A.J., Gilad, Y., Odom, D.T., and Flicek, P. (2013). Co-binding by YY1 identifies the transcriptionally active, highly conserved set of CTCFbound regions in primate genomes. Genome Biol. 14, R148-15.

1435 Schwarzer, W., Abdennur, N., Goloborodko, A., Pekowska, A., Fudenberg, G., Loe-Mie, Y., Fonseca, N.A., H Haering, C., Mirny, L., and Spitz, F. (2017). Two independent modes of chromatin organization revealed by cohesin removal. Nature 551, 51-56.

1438 Seitan, V.C., Faure, A.J., Zhan, Y., McCord, R.P., Lajoie, B.R., Ing-Simmons, E., Lenhard, B., 1439 Giorgetti, L., Heard, E., Fisher, A.G., et al. (2013). Cohesin-based chromatin interactions enable 1440 regulated gene expression within preexisting architectural compartments. Genome Res. 23, $1441 \quad 2066-2077$.

1442 Soardi, F.C., Machado-Silva, A., Linhares, N.D., Zheng, G., Qu, Q., Pena, H.B., Martins, T.M.M., Vieira, H.G.S., Pereira, N.B., Melo-Minardi, R.C., et al. (2017). Familial STAG2 germline mutation defines a new human cohesinopathy. NPJ Genom Med 2, 7-11.

1445 Sofueva, S., Yaffe, E., Chan, W.-C., Georgopoulou, D., Rudan, M.V., Mira-Bontenbal, H., 1446 Pollard, S.M., Schroth, G.P., Tanay, A., and Hadjur, S. (2013). Cohesin-mediated interactions 1447 organize chromosomal domain architecture. Embo J. 32, 3119-3129.

1448 Strom, A.R., Emelyanov, A.V., Mir, M., Fyodorov, D.V., Darzacq, X., and Karpen, G.H. (2017). 
Phase separation drives heterochromatin domain formation. Nature 547, 241-245.

1450 Subramanian, A., Tamayo, P., Mootha, V.K., Mukherjee, S., Ebert, B.L., Gillette, M.A., Paulovich, A., Pomeroy, S.L., Golub, T.R., Lander, E.S., et al. (2005). Gene set enrichment analysis: a knowledge-based approach for interpreting genome-wide expression profiles. Proc Natl Acad Sci USA 102, 15545-15550.

1454 Tapial, J., Ha, K.C.H., Sterne-Weiler, T., Gohr, A., Braunschweig, U., Hermoso-Pulido, A., Quesnel-Vallières, M., Permanyer, J., Sodaei, R., Marquez, Y., et al. (2017). An atlas of alternative splicing profiles and functional associations reveals new regulatory programs and genes that simultaneously express multiple major isoforms. Genome Res. 27, 1759-1768.

Vietri Rudan, M., Barrington, C., Henderson, S., Ernst, C., Odom, D.T., Tanay, A., and Hadjur, S. (2015). Comparative Hi-C reveals that CTCF underlies evolution of chromosomal domain architecture. CellReports 10, 1297-1309.

1461 Viny, A.D., Bowman, R.L., Liu, Y., Lavallée, V.-P., Eisman, S.E., Xiao, W., Durham, B.H., 1462 Navitski, A., Park, J., Braunstein, S., et al. (2019). Cohesin Members Stag1 and Stag2 Display 1463 Distinct Roles in Chromatin Accessibility and Topological Control of HSC Self-Renewal and 1464 Differentiation. Cell Stem Cell 25, 682-696.e688.

1465 Wagner, A., Regev, A., and Yosef, N. (2016). Revealing the vectors of cellular identity with 1466 single-cell genomics. Nature Publishing Group 34, 1145-1160.

1467 Wendt, K.S., Yoshida, K., Itoh, T., Bando, M., Koch, B., Schirghuber, E., Tsutsumi, S., Nagae, 1468 G., Ishihara, K., Mishiro, T., et al. (2008). Cohesin mediates transcriptional insulation by CCCTC-binding factor. Nature 451, 796-801.

Whyte, W.A., Orlando, D.A., Hnisz, D., Abraham, B.J., Lin, C.Y., Kagey, M.H., Rahl, P.B., Lee, T.I., and Young, R.A. (2013). Master transcription factors and mediator establish superenhancers at key cell identity genes. Cell 153, 307-319.

1473 Winters, T., McNicoll, F., and Jessberger, R. (2014). Meiotic cohesin STAG3 is required for 1474 chromosome axis formation and sister chromatid cohesion. Embo J. 33, 1256-1270.

1475 Wutz, G., Várnai, C., Nagasaka, K., Cisneros, D.A., Stocsits, R.R., Tang, W., Schoenfelder, S., Jessberger, G., Muhar, M., Hossain, M.J., et al. (2017). Topologically associating domains and chromatin loops depend on cohesin and are regulated by CTCF, WAPL, and PDS5 proteins. Embo J. 36, 3573-3599. interact with the SA2 subunit of the cohesin complex and are required for cohesin-dependent insulation activity. Mol. Cell. Biol. 31, 2174-2183.

1482 Yuan, B., Neira, J., Pehlivan, D., Santiago-Sim, T., Song, X., Rosenfeld, J., Posey, J.E., Patel, 1483 V., Jin, W., Adam, M.P., et al. (2019). Clinical exome sequencing reveals locus heterogeneity and phenotypic variability of cohesinopathies. Genet Med 21, 663-675.

1485 Yusufzai, T.M., Tagami, H., Nakatani, Y., and Felsenfeld, G. (2004). CTCF tethers an insulator 1486 to subnuclear sites, suggesting shared insulator mechanisms across species. Molecular Cell 13, 


\section{291-298.}

1488 Zuin, J., Dixon, J.R., van der Reijden, M.I.J.A., Ye, Z., Kolovos, P., Brouwer, R.W.W., van de 1489 Corput, M.P.C., van de Werken, H.J.G., Knoch, T.A., van IJcken, W.F.J., et al. (2014). Cohesin 1490 and CTCF differentially affect chromatin architecture and gene expression in human cells. Proc. 1491 Natl. Acad. Sci. U.S.a. 111, 996-1001. 
Figure 1.

Pezic et al.

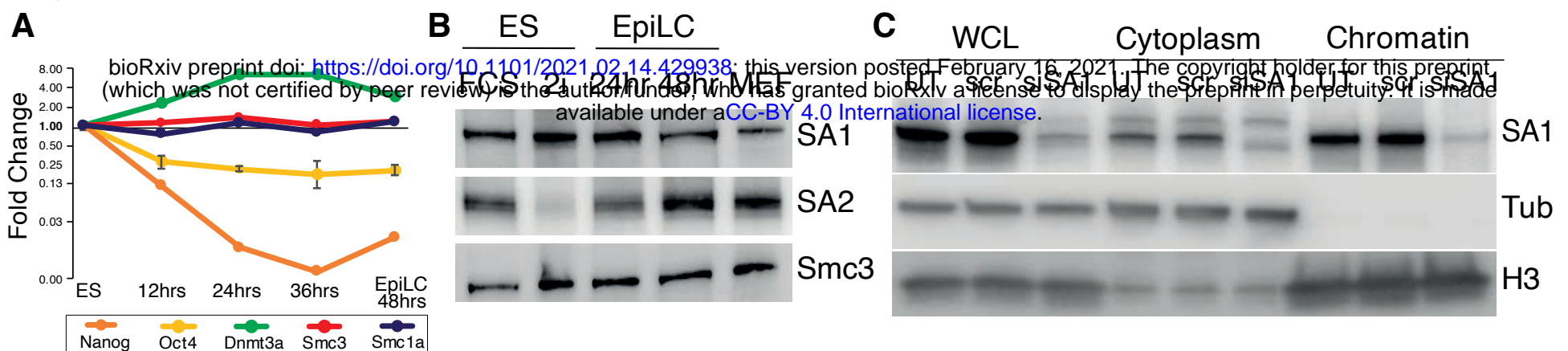

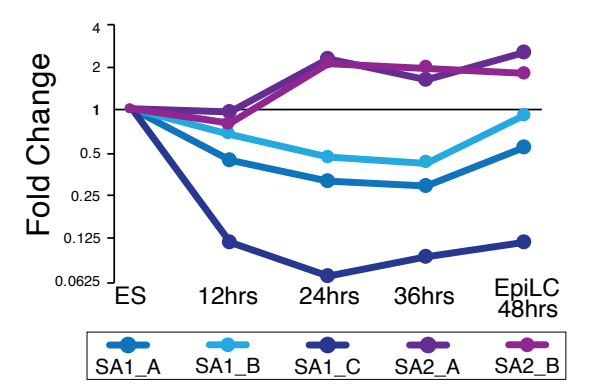

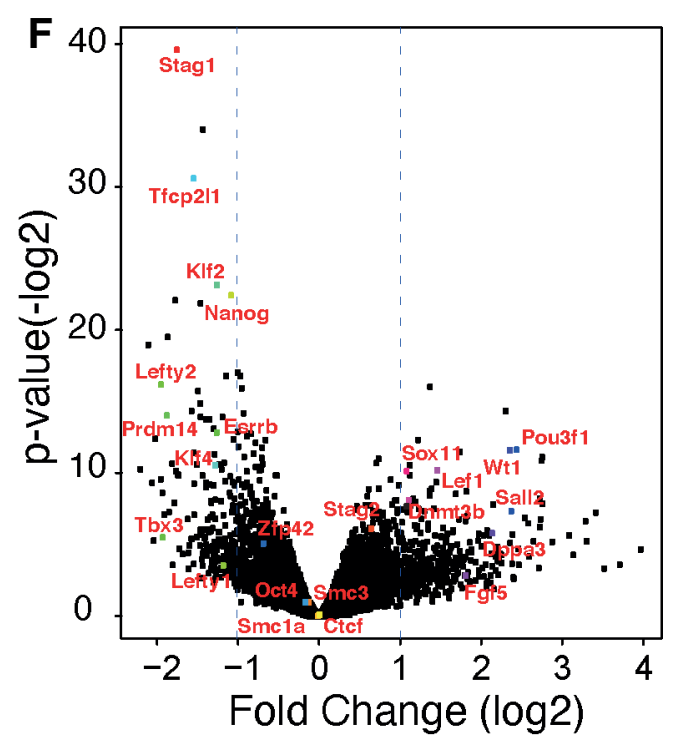

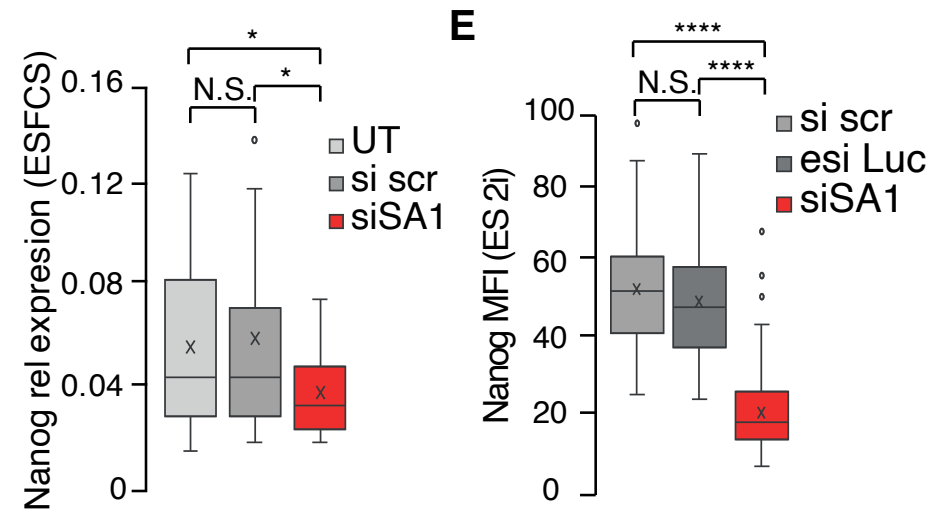

\section{G NAIVE PLURIPOTENCY}

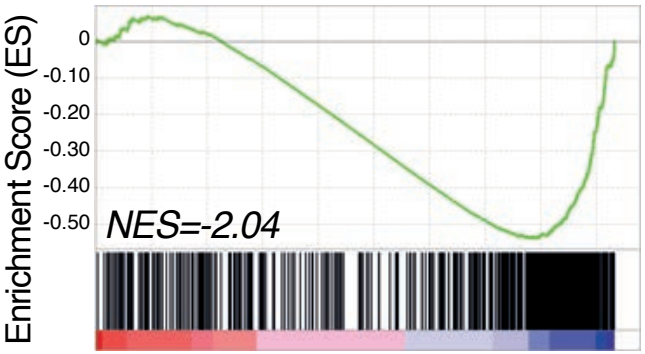

$\mathrm{SA} 1^{\mathrm{NG}-\mathrm{FKBP}}$
UP in

SA1SP KD

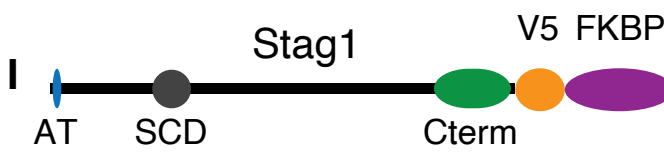

DOWN in

SA1SP KD

Exp1
Exp2
Exp3

si scr siSA1 SP

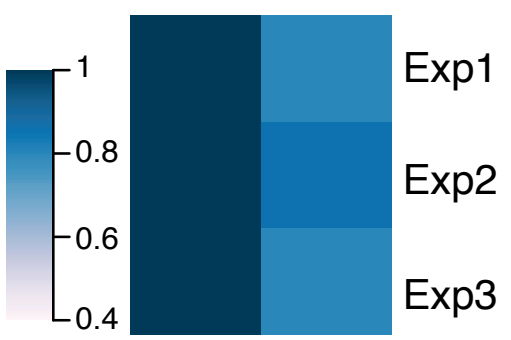

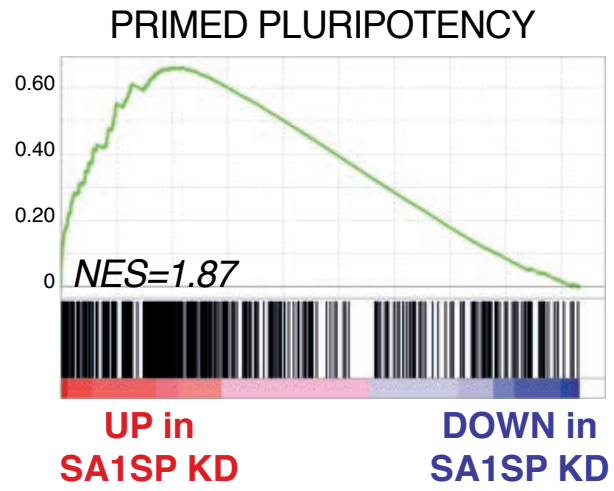

J

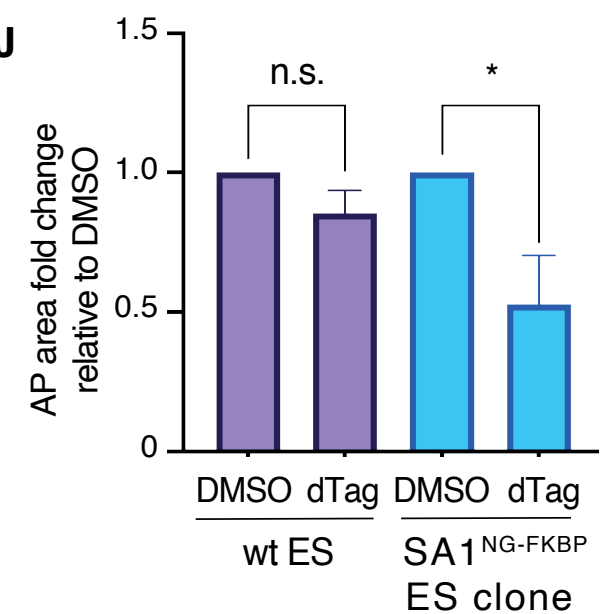


Figure 2.

Pezic et al.

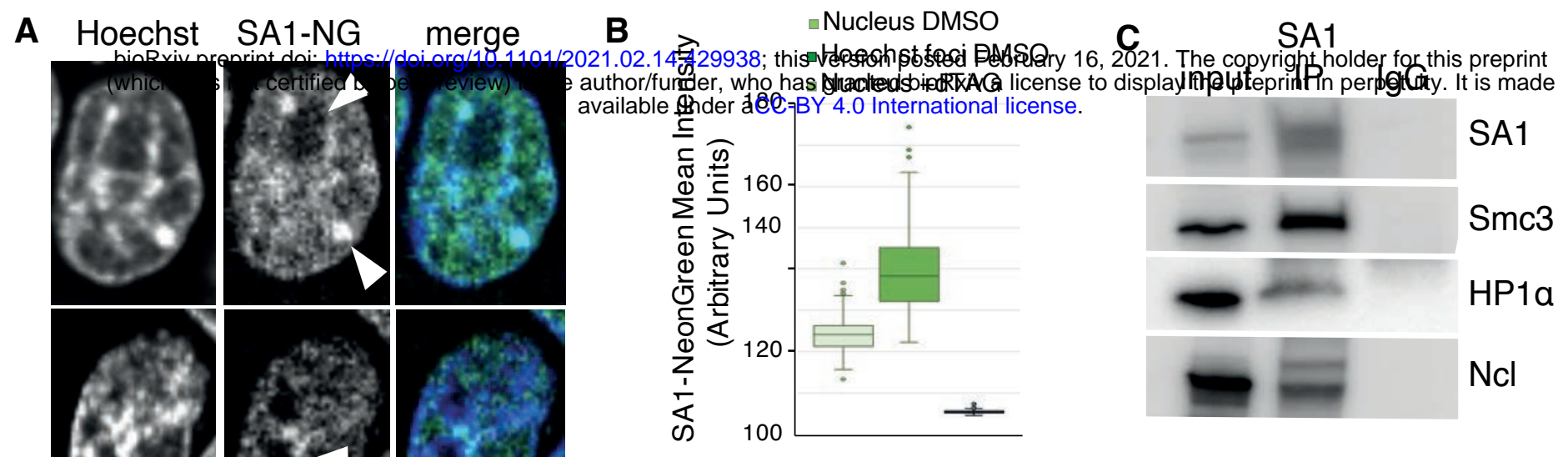

E

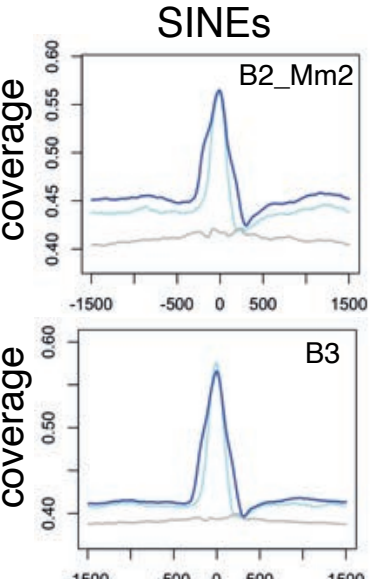

LINEs

LTRs
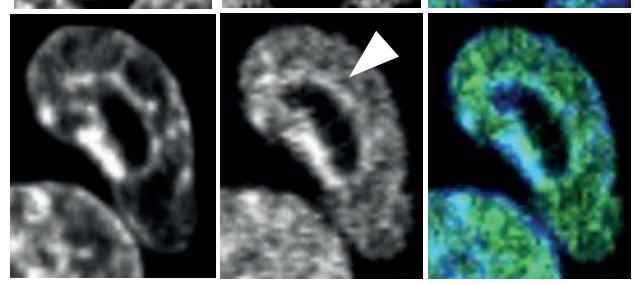

D

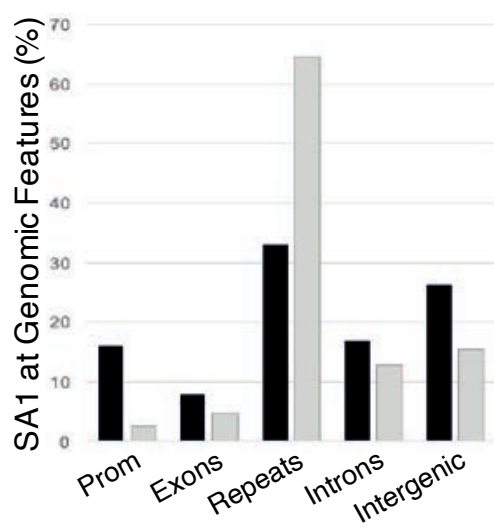

- SA 1 bound Shuffled
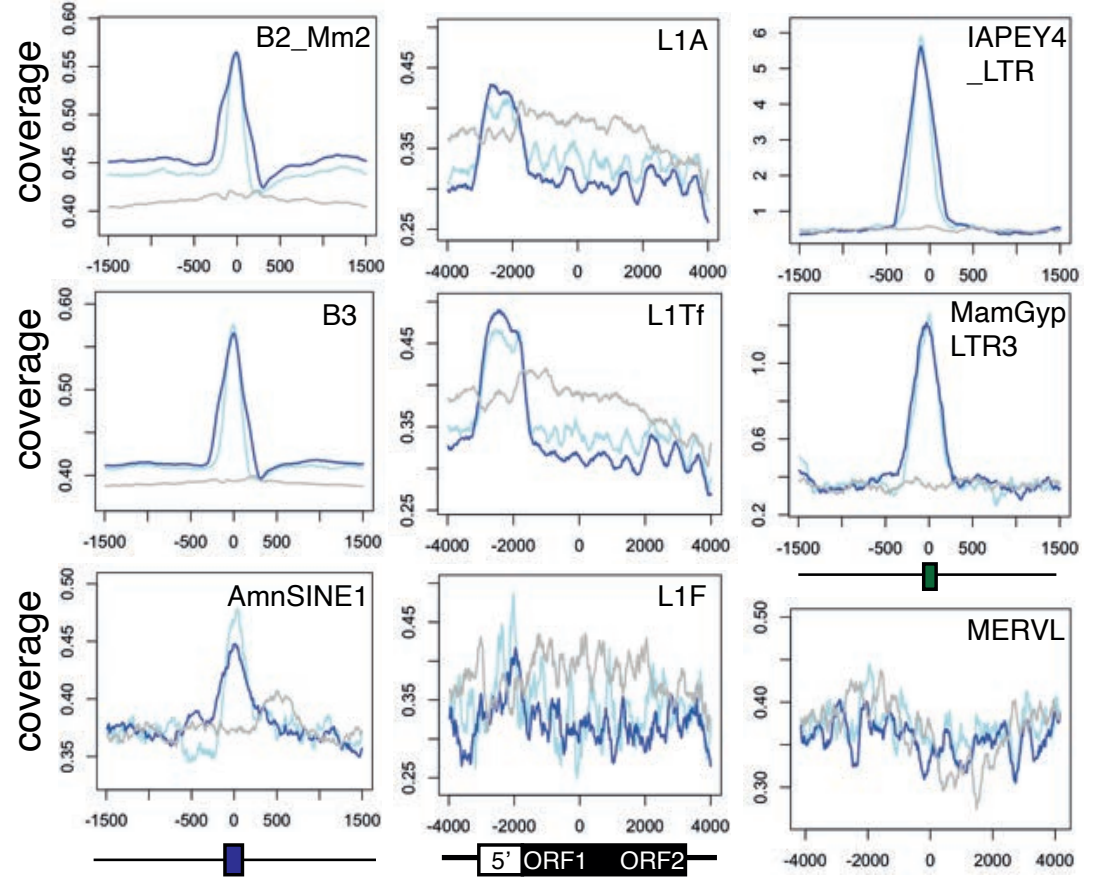

- SA1 ChIP Rep1 — SA1 ChIP Rep2 - input
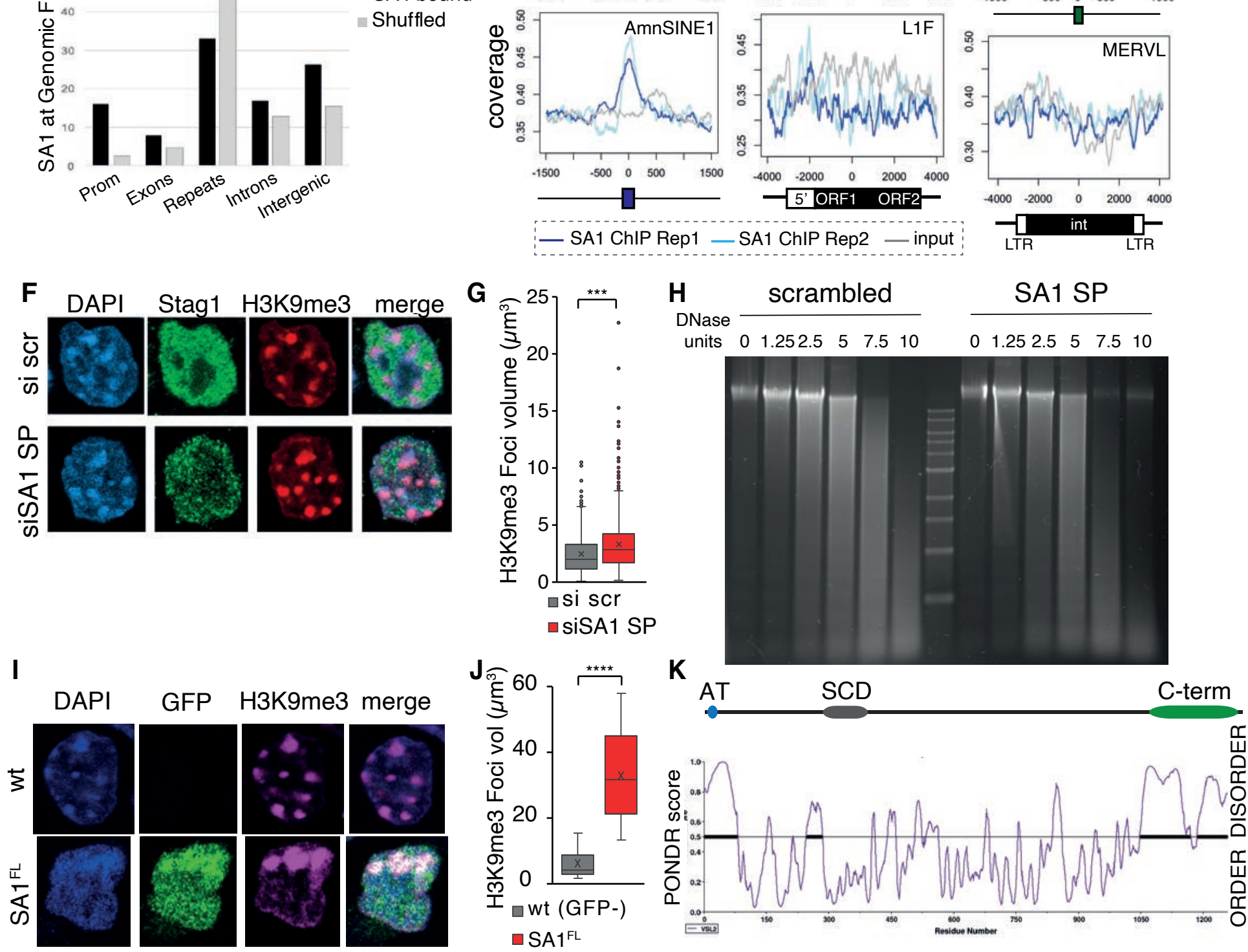
Figure 3.

Pezic et al.
A 5 ' RARCE
B
C 3'RACE
E SATS- altex1- ex1- ex4- ex6-
(W.
$\mathrm{kb}$

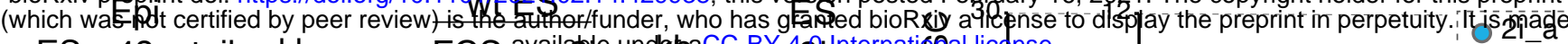
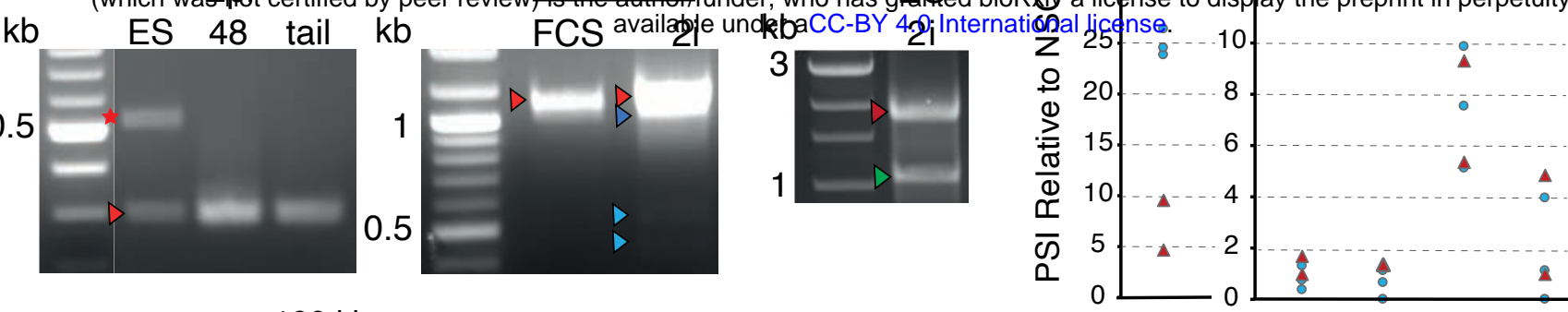
○ 2i_b
o 2i_c
$\triangle F C S \_a$
$1-D$
$\triangle F C S \_b$

$100 \mathrm{~kb}$

Stag1 (SA1) gene

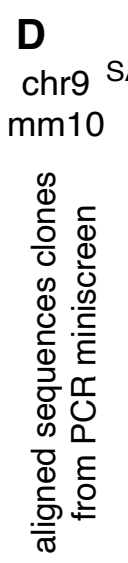

can altex

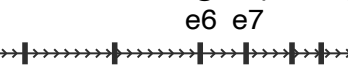

e25

ATS

$(m)$
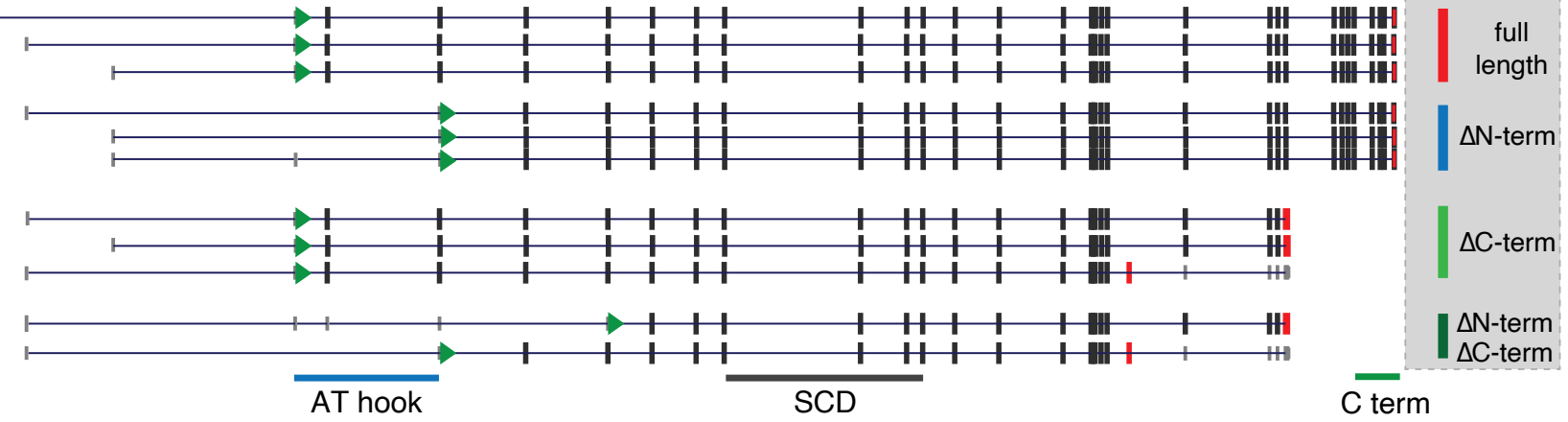

C term

$\mathbf{F}$

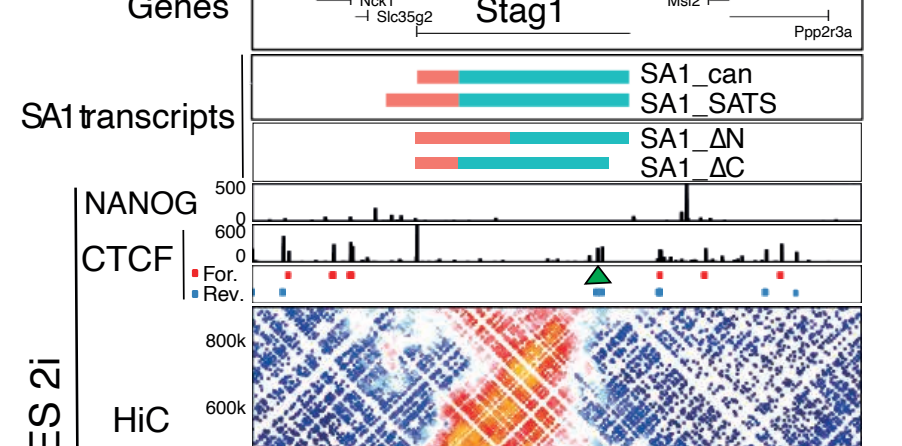

TADep

CTCF

[Rep. 1 .
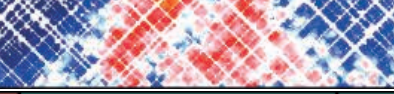

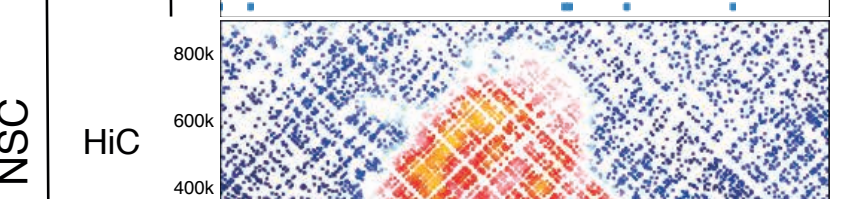

G

AT
hook

SCD

C term

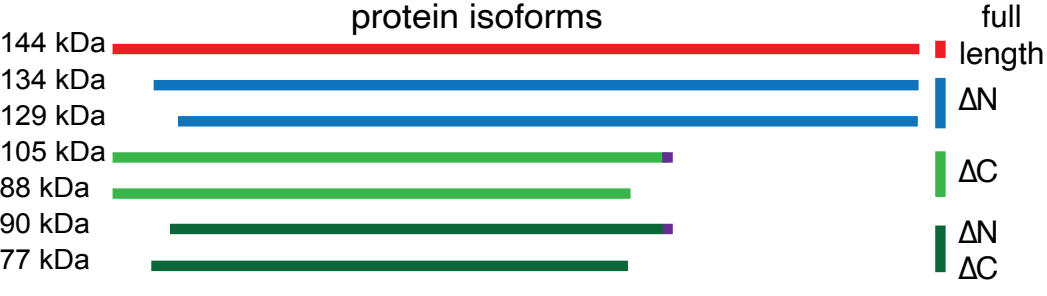

$\mathrm{H} \odot$

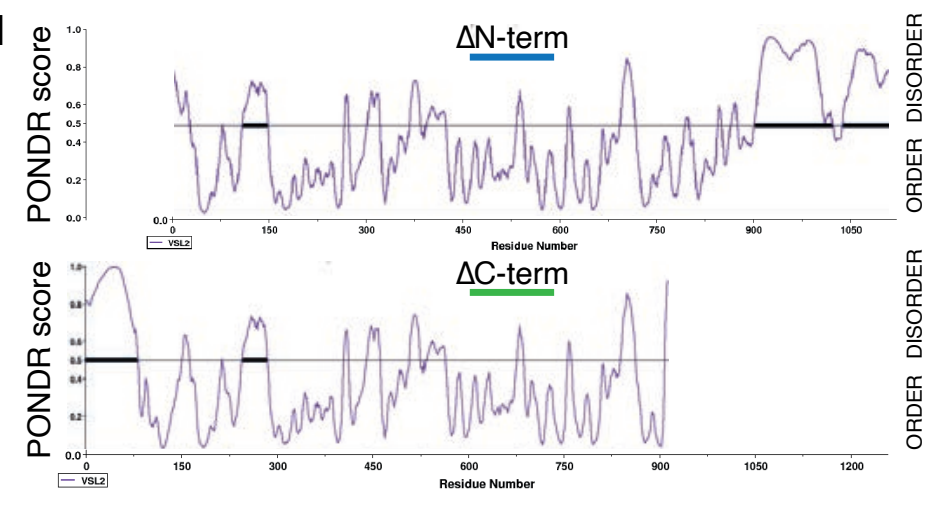

si

$S A 1^{\text {NG-FKBP }}$

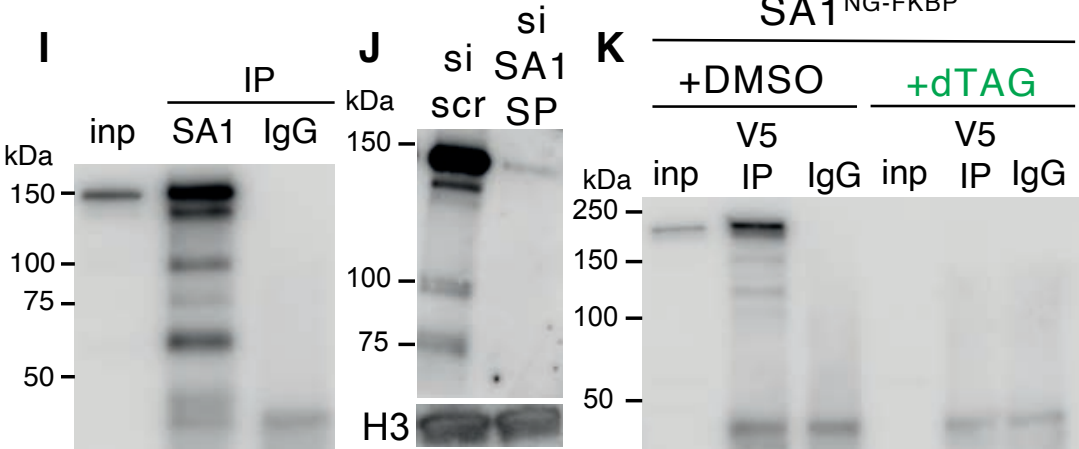


Figure 4.

Pezic et al.

A

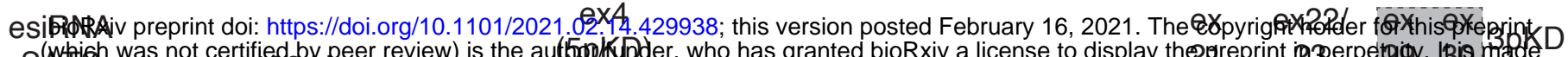

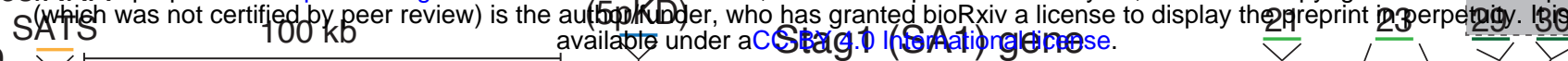

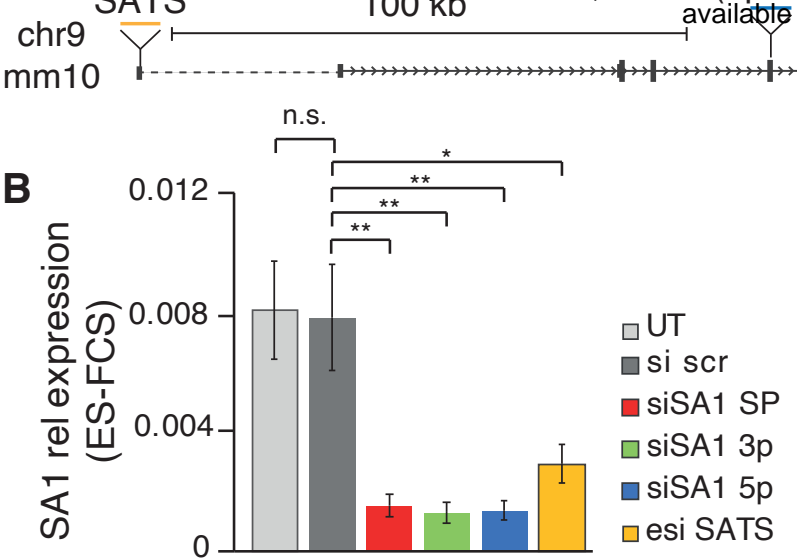

D

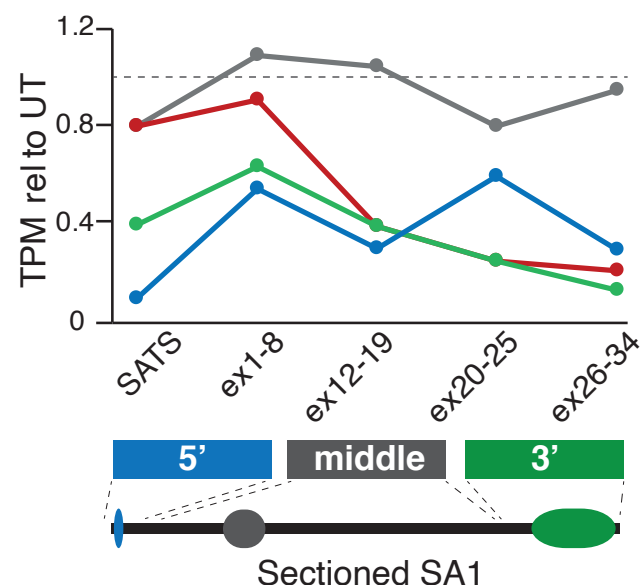

F

$S A 1^{N G-F K B P}$

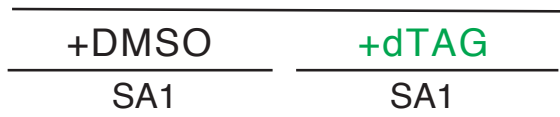

$\mathrm{kDa}$ inp IP $\lg G$ inp IP $\lg G$

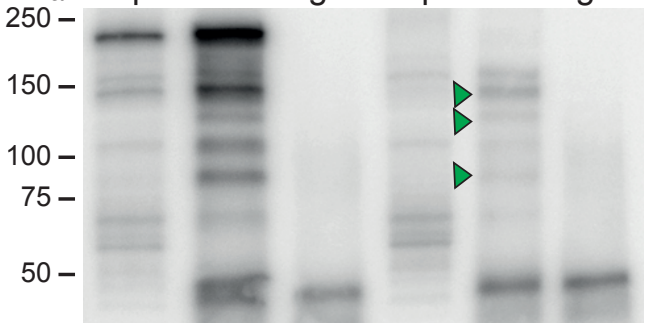

- si scr

$\rightarrow$ siSA1 SP

E 5'RACE

3' RACE

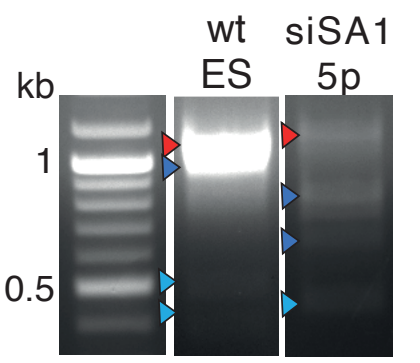

si si si

si SA1 SA1 SA1

- siSA1 5p

G
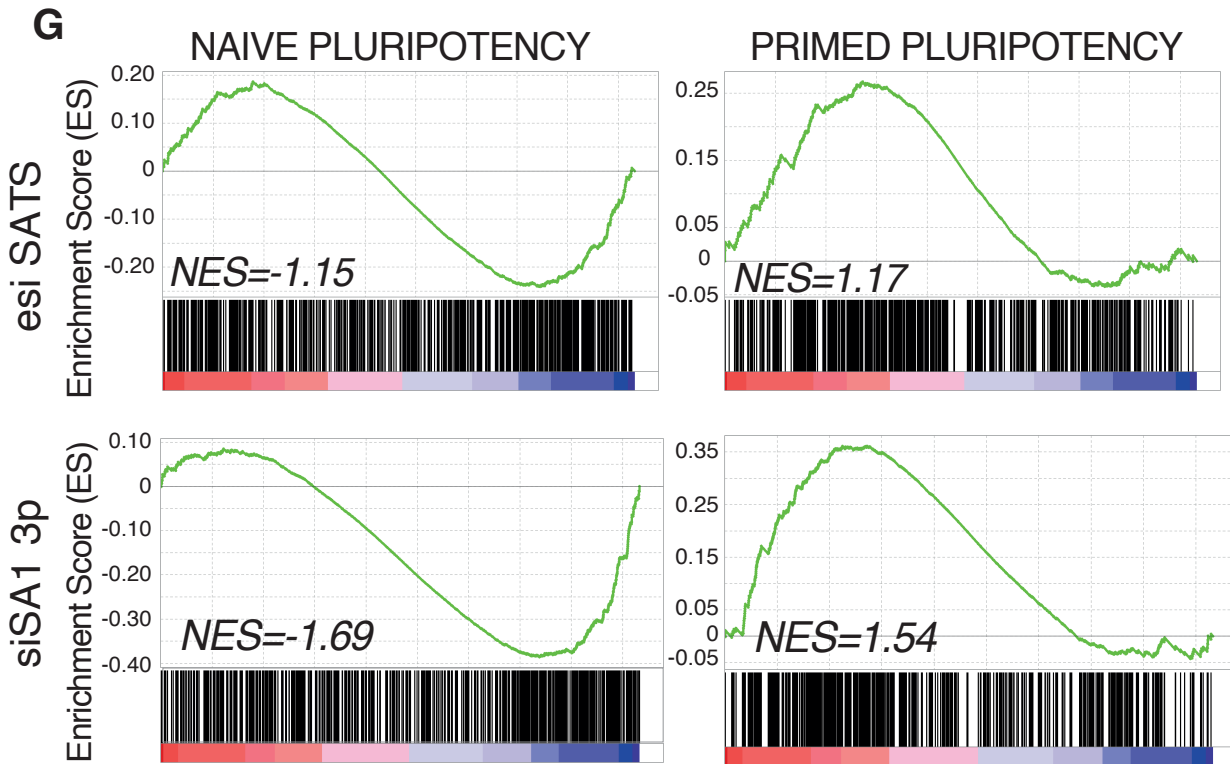

H

SiSA1 esi siSA1 siSA1 si scr SP SATS $3 p \quad 5 p$

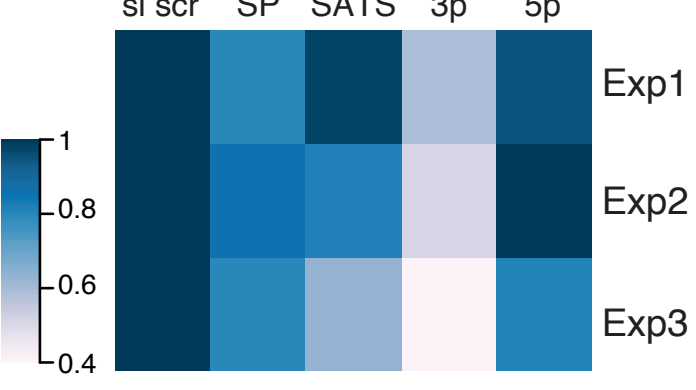

을

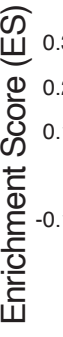

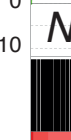

NES $=1.56$

$k b \quad$ scr SP $3 p \quad 5 p$

3

1
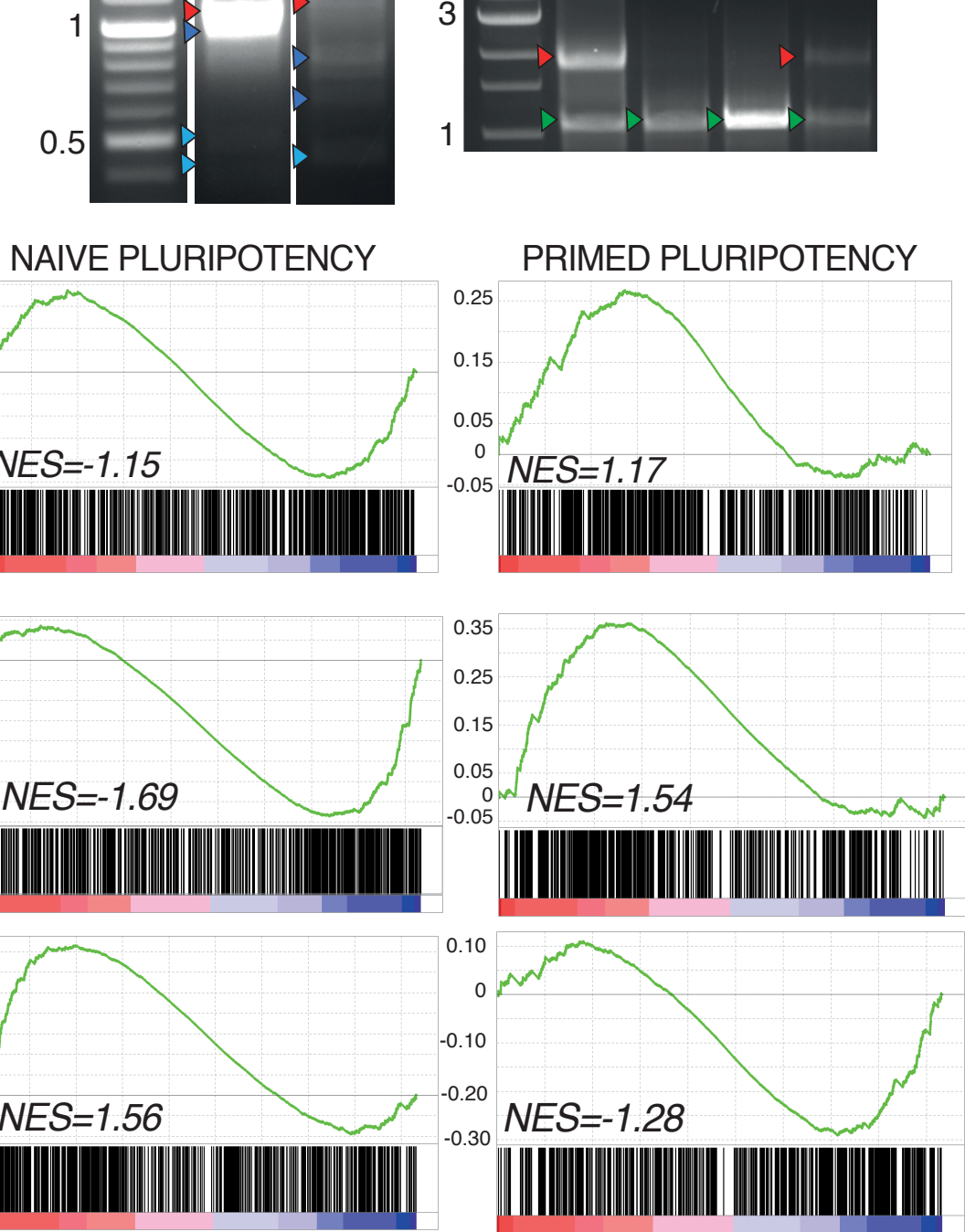

UP in

Stag1 KD
DOWN in

Stag1 KD Stag1 KD
DOWN in

Stag1 KD 
Figure 5.

Pezic et al.

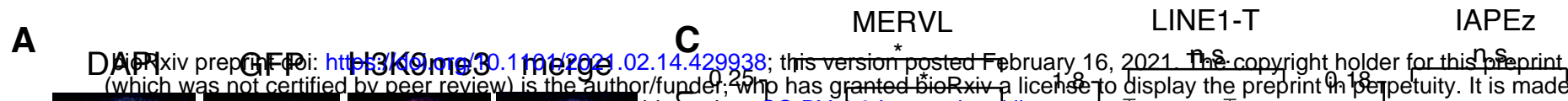
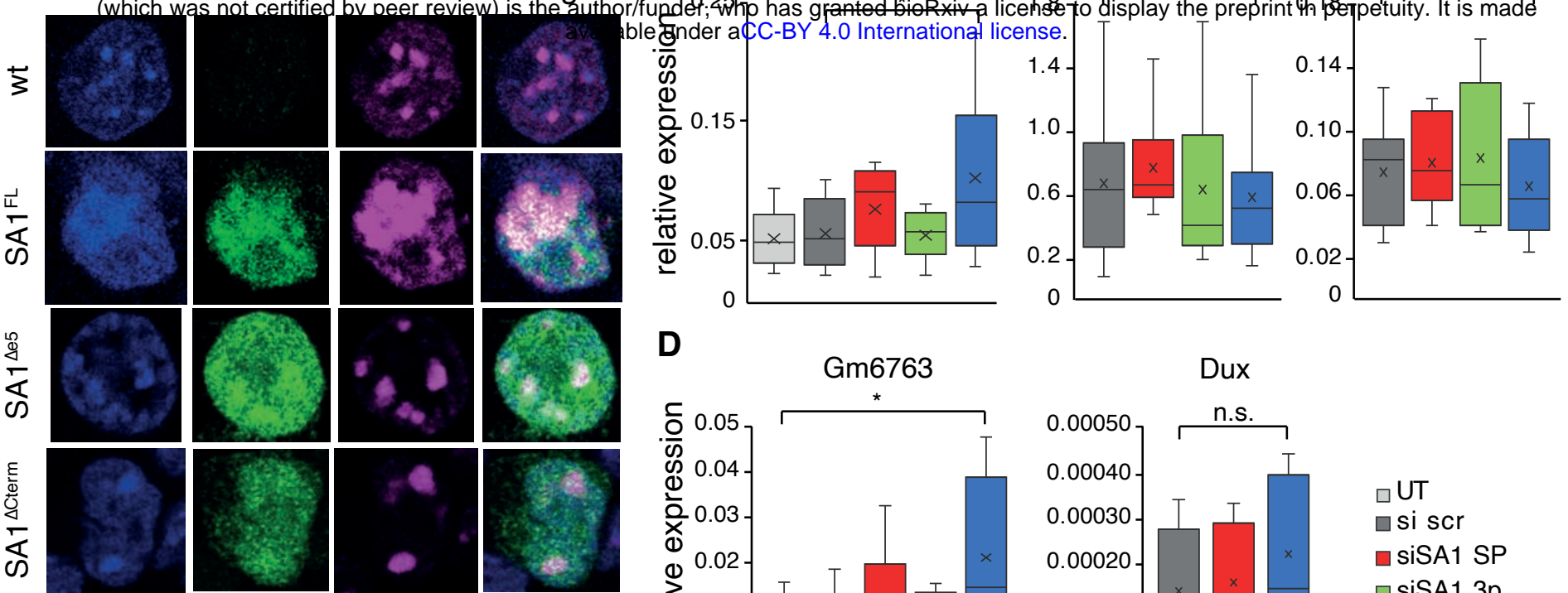

D
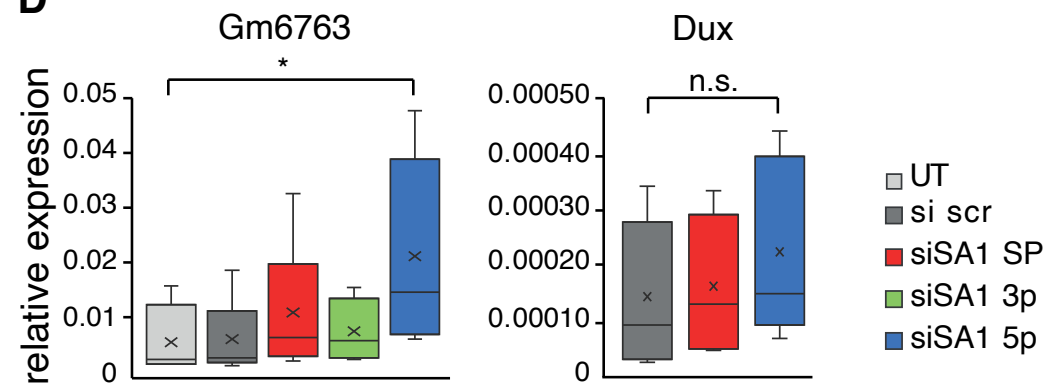

B

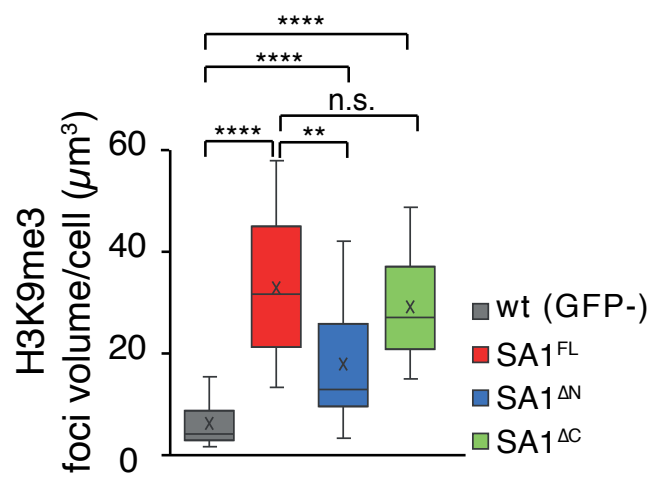

E

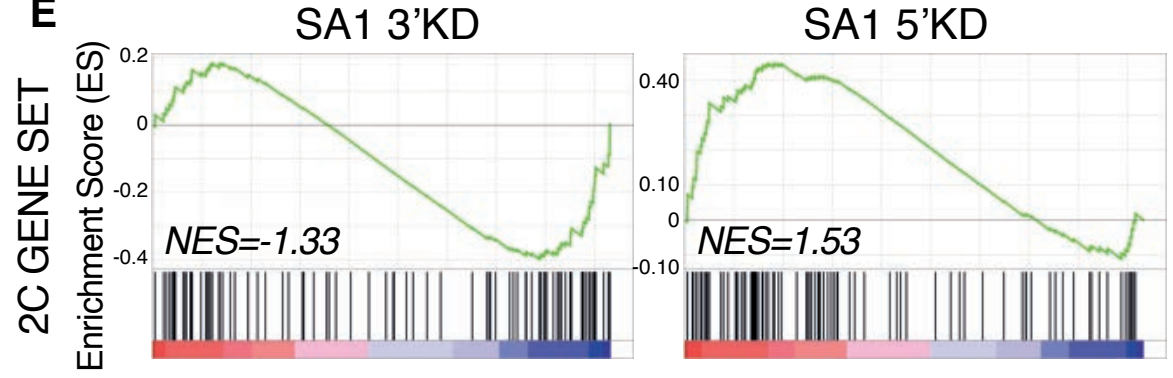

$\mathbf{F}$

siSA1 $5 p$ G
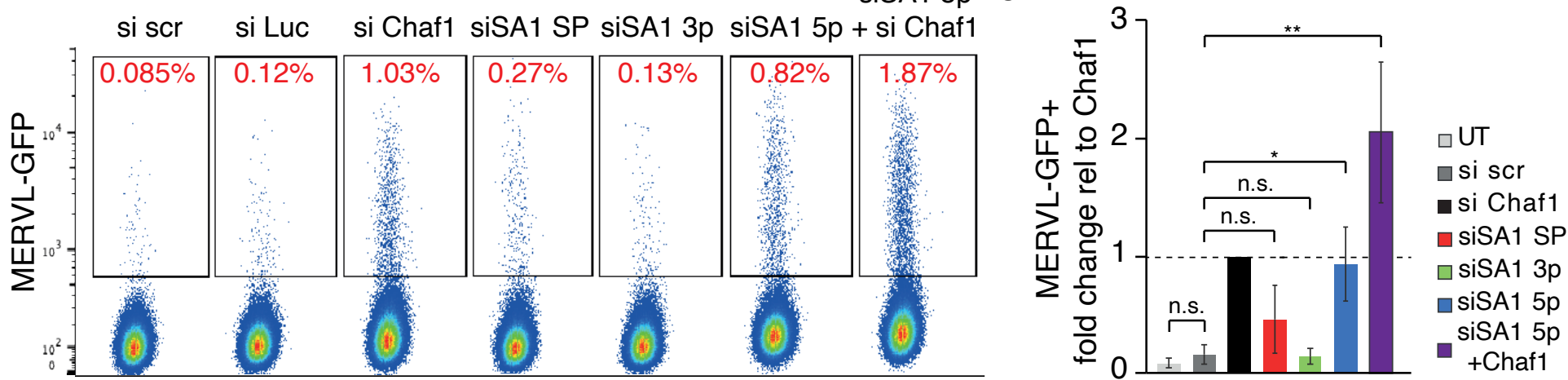

$\mathbf{H}$

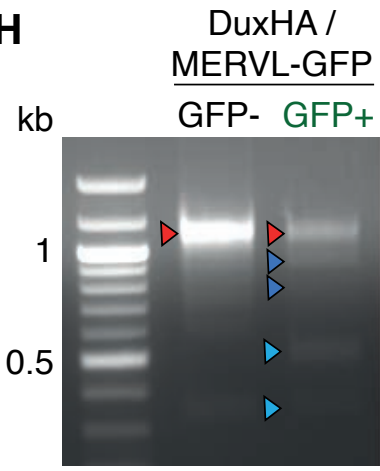
DuxHA / I
$\frac{\text { MERVL-GFP }}{\text { GFP- GFP+ }}$

GGACACTGACATGGACTGAAGGAGTAGAAAAGCTCTTGCTCTAGCTCCATCGC CTGCTTGCTGTGTGAGACTGAGTAACTGCTAGATCCTTGGACTTCCATTCACAG CTGCGACTGAACAATTGTTGGGAATTGGGCTGCCGACTGACAGTGGTGACTAC CCCCTTACAATGCCTGGTCCTCAGTGGAAAAAATTTCGTTCCAATTTTTGTGAAT TTATTGGAGTCCTGATTCGACAGTGTCAATATAGCATAATTTATGATGAATATATG ATGGACACCGTAATTTCCCTTTTGACTGGTTTGTCAGACTCCCAAGTCAGAGC TTTTAGGCATACAAGTACCCTTGCTGCAATGAAGCTGATGACTGCTCTGGTGAA TGTTGCTTTAAACCTCAGTATTCATCAAGATAATACACAGAGGCAATATGAAGCT GAGAGAAATAAAATGATTGGGAAGAGAGCCAATGAAAGACTGGAGTTACTACTT CAGAAACGTAAAGAG
- 5'GeneRacer oligo
- MT2_MERVL
- Stag1 exon $7+$ exon 8

J

SA1

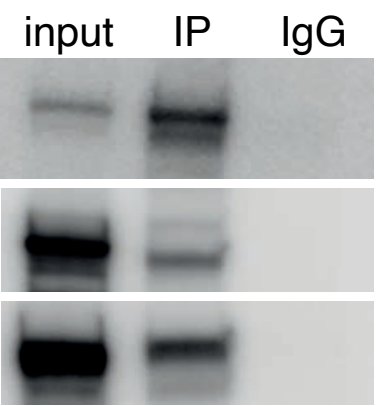

Stag1

Nucleolin

Trim28 
Figure 6.

Pezic et al.

A $\quad \mathrm{DAPI}+\mathrm{Nascent}$

B

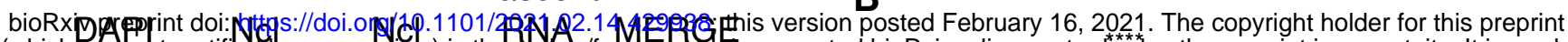
(which was not certified hy neer review) is the author/fynder. who has granted bioRxiv a license to ditwlay the preprint in perpetuity. It is made
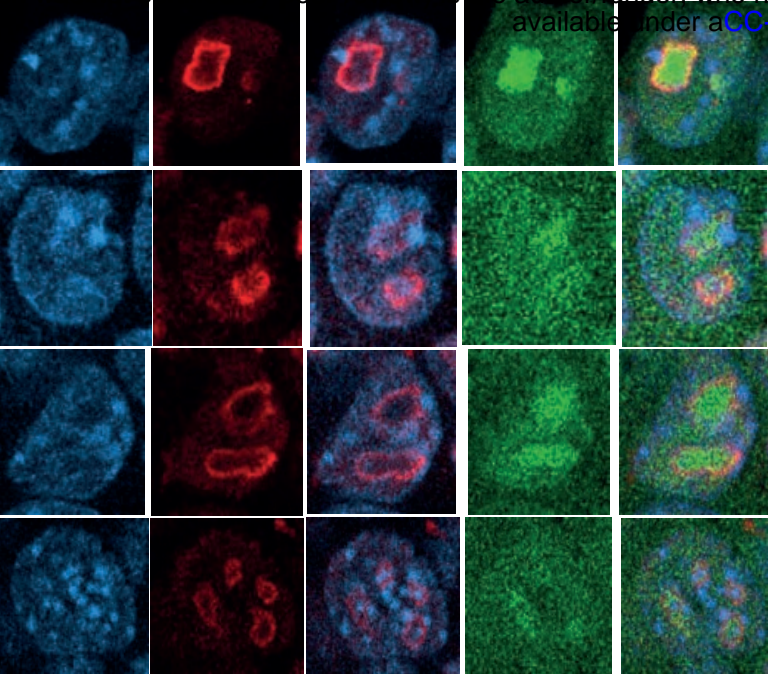

BY 4.0 International license. ****

SiSA1 SP

siSA13p
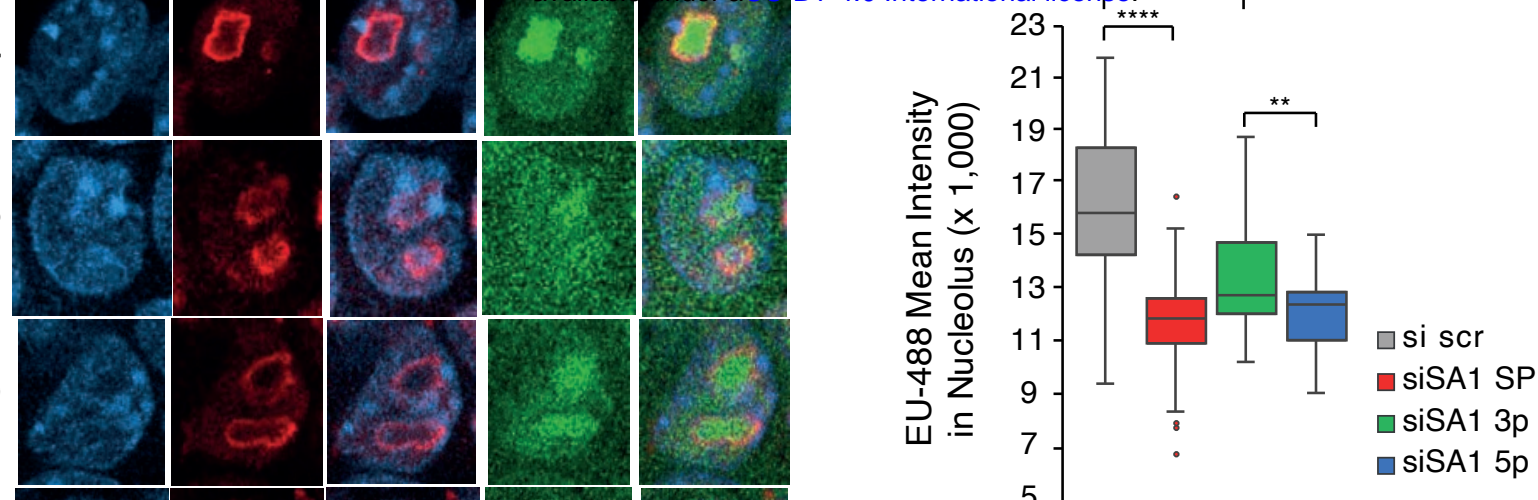

siSA15p
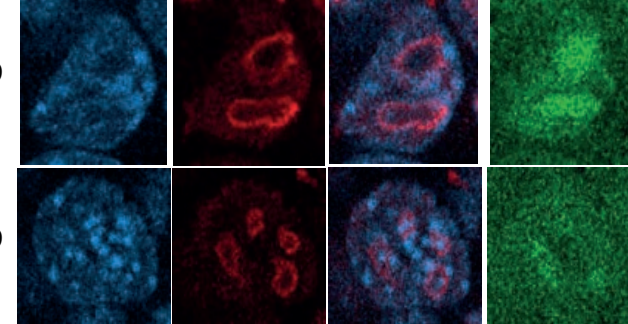

C

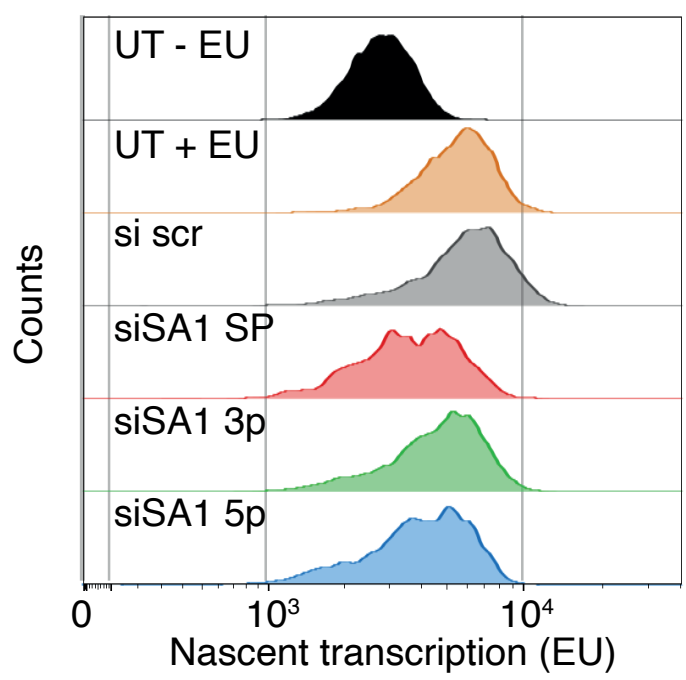

E

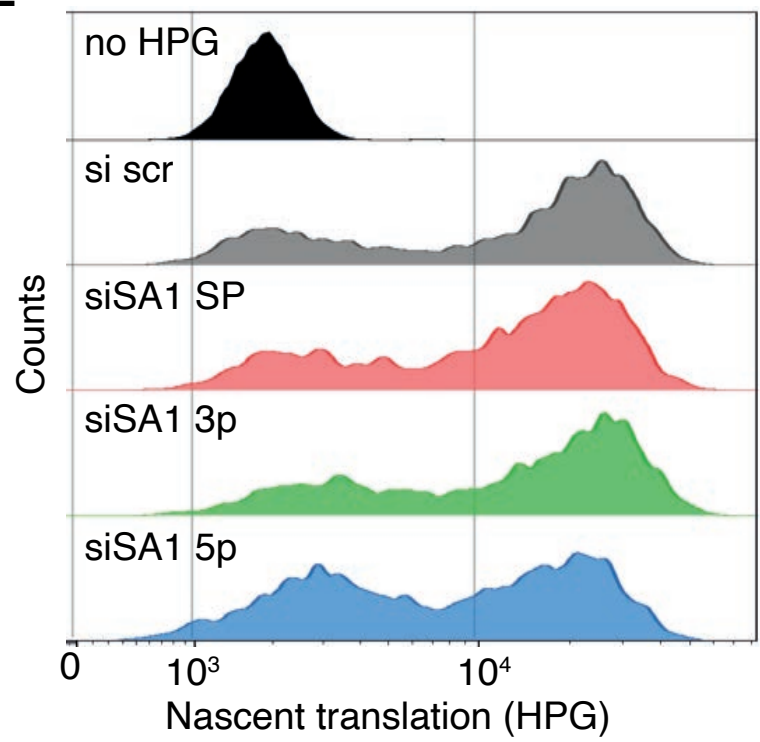

D

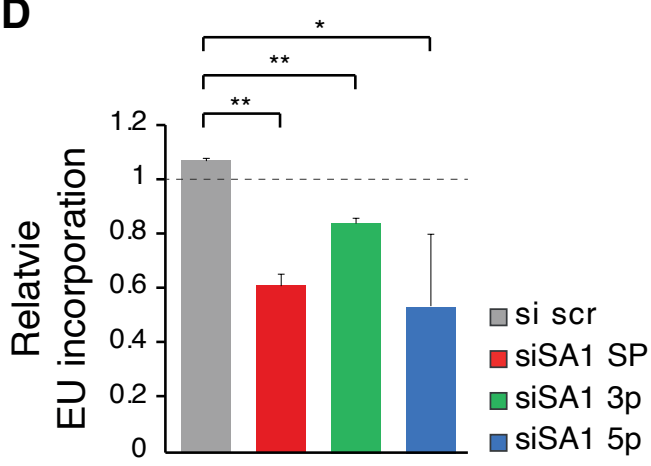

F

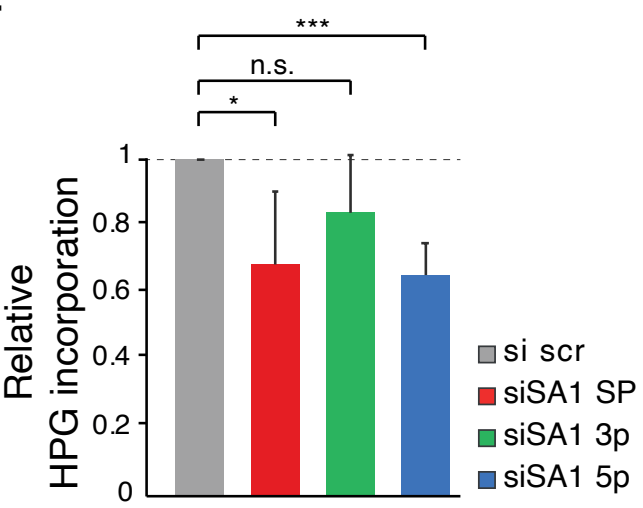

